\title{
Complex geomorphologic assemblage of terrains in association with the banded terrain in Hellas basin, Mars
}

X. Diot ${ }^{1,2}$, M.R. El-Maarry ${ }^{3}$, F. Schlunegger ${ }^{1}$, K.P. Norton ${ }^{4}$, N. Thomas ${ }^{2,3}$, P.M. Grindrod ${ }^{5,6}$ and M. Chojnacki ${ }^{7}$

${ }^{1}$ Institut für Geologie Universität Bern, Baltzerstrasse 1-3 CH-3012 Berne, Switzerland.

${ }^{2}$ Center for Space and Habitability, Universität Bern, Sidlerstrasse 5 CH- 3012 Berne, Switzerland.

${ }^{3}$ Physikalisches Institut, Universität Bern, Sidlerstrasse 5 CH- 3012 Berne, Switzerland.

${ }^{4}$ School for Geography, Environment and Earth Science, Victoria University of Wellington, New Zealand.

${ }^{5}$ Department of Earth and Planetary Sciences, Birkbeck, University of London, London, UK ${ }^{6}$ Centre for Planetary Sciences at UCL/Birkbeck, London, UK.

${ }^{7}$ Lunar and Planetary Laboratory, University of Arizona, Tucson, AZ 85721, United States

\section{Corresponding author}

Xavier Diot

Institut für Geologie Universität Bern

Baltzerstrasse 1-3 CH-3012, Switzerland

E-mail address: xavier.diot@csh.unibe.ch

Number of Tables: 2

Number of Figures: 16

Submitted to Planetary \& Space Science 


\section{Abstract}

Hellas basin acts as a major sink for the southern highlands of Mars and is likely to have recorded several episodes of sedimentation and erosion. The north-western part of the basin displays a potentially unique Amazonian landscape domain in the deepest part of Hellas, called "banded terrain", which is a deposit characterized by an alternation of narrow band shapes and inter-bands displaying a sinuous and relatively smooth surface texture suggesting a viscous flow origin. Here we use high-resolution (HiRISE and CTX) images to assess the geomorphological interaction of the banded terrain with the surrounding geomorphologic domains in the NW interior of Hellas to gain a better understanding of the geological evolution of the region as a whole. Our analysis reveals that the banded terrain is associated with six geomorphologic domains: a central plateau named Alpheus Colles, plain deposits (P1 and P2), reticulate (RT1 and RT2) and honeycomb terrains. Based on the analysis of the geomorphology of these domains and their cross-cutting relationships, we show that no widespread deposition post-dates the formation of the banded terrain, which implies that this domain is the youngest and latest deposit of the interior of Hellas. Therefore, the level of geologic activity in the NW Hellas during the Amazonian appears to have been relatively low and restricted to modification of the landscape through mechanical weathering, aeolian and periglacial processes. Thermophysical data and cross-cutting relationships support hypotheses of modification of the honeycomb terrain via vertical rise of diapirs such as ice diapirism, and the formation of the plain deposits through deposition and remobilization of an ice-rich mantle deposit. Finally, the observed gradual transition between honeycomb and banded terrain suggests that the banded terrain may have covered a larger area of the NW interior of Hellas in the past than previously thought. This has implications on the understanding of the evolution of the deepest part of Hellas.

Keywords: Mars, surface; Geomorphological processes; Hellas basin 


\section{Introduction}

A large part of the geological and hydrological history of Mars is preserved in the Noachian highlands that cover approximately half of the planet (Wilson et al., 2010). In its southern regions, widespread valley and channel networks are observed (e.g. Carr and Chuang, 1997; Forsythe and Blackwelder, 1998; Cabrol and Grin, 2001; Howard et al., 2005; Ansan et al., 2008). Some of these valleys terminate in craters and basins (Maxwell and Craddock, 1995; Howard et al., 2005) in the form of fans or alluvial deposits (Wilson et al., 2012). Also in this area, several ancient craters display putative shorelines and light-toned layered interior deposits that suggest that they may have harbored paleolakes (De Hon, 1992; Wilson et al., 2007; Cabrol and Grin, 2010; Ansan et al., 2011). Thus, erosional and sediment transport processes had a significant impact on the geomorphic and stratigraphic development of the southern highlands, particularly in association with impact craters, where multiple sedimentary successions have been documented.

In addition to the geomorphic evidence for fluvial deposits and erosion at the southern highlands' surface in ancient times, numerous hydrous minerals such as hydrated-silica, phyllosilicates and secondary minerals including chlorides have been detected spectrally in the southern highlands (e.g. Osterloo et al., 2008, 2010; Carter et al., 2013; Ehlmann et al., 2011, 2014). The formation of these minerals, which usually requires significant volumes of liquid water, combined with the occurrence of large drainage network systems suggests that hydrologic processes have widely shaped the landscape of Mars (Carr and Chuang, 1997; Crown et al., 2005; Matsubara et al., 2013, El-Maarry et al., 2014), especially in terrains surrounding Hellas basin (Wilson et al., 2007; Ansan et al., 2011; Ehlmann et al., 2014). 
Due to its size, Hellas basin represents a major sink for the surrounding drainage network systems (e.g. Carr, 1995; Mest et al., 2001; Crown et al., 2005; Wilson et al., 2010; De Blasio, 2014) and could thus have recorded several episodes of sedimentation and erosion through volcanic, fluvial, glacial and aeolian processes (e.g. Moore and Edgett, 1993; Tanaka and Leonard, 1995; Leonard and Tanaka, 2001; Wilson et al., 2010; Bernhardt et al., 2015). Despite substantial constraints on observing Hellas basin caused by the high atmospheric aerosol content, the region has been a regular target for observation by most Mars orbiting missions (e.g. Simpson et al., 1979; Moore and Edgett; 1993; Martin and Richardson, 1993; Edwards et al., 2001; Krause and Grosfils, 2001; Smith et al., 1999, 2001; Kostama et al., 2001; Albee, 2002; Ormö and Komatsu, 2003; Plaut, 2003; Encrenaz et al., 2006; Graf et al., 2005; Grassi et al., 2007; McEwen et al., 2002, 2007 and 2010; Malin et al., 2007; Murchie et al., 2007). Studies that are based on Viking Orbiter Infrared Thermal Mapper (IRTM) data suggested that the ground of the basin is made up of indurated fine-grained material, especially in its lowest part where outcrops of bedrock are considered to be absent (Moore and Edgett, 1993). Using Viking images, Tanaka and Leonard (1995) studied the geologic and geomorphic architecture of the basin and proposed that Hellas was mainly filled by volcanic flows, which were subsequently modified by fluvial and aeolian processes. Alternatively, geomorphic studies suggested that the surface material in the interior part of Hellas was most likely formed by aqueous and glacial processes (Kargel and Strom, 1991; Wilson et al., 2010). Based on high-resolution images from the Mars Orbiter Camera (MOC), Moore and Wilhelms (2001) observed bright layered deposits along several contours and a series of polygonal depressions referred to as honeycomb material. These authors have speculated that this morphology could reflect imprints of falling ice-blocks on the nonconsolidated mud at the surface. Recently, Diot et al. (2014) described a possibly unique terrain type referred to as "banded terrain" (Figs. 1A and 2). The banded terrain displays an 
alternation of narrow bands and inter-bands where the sinuous morphology was attributed to viscous flow behavior. This terrain is localized in the northwestern interior of Hellas, mainly in the deepest part of the basin. Mapping and morphometric analysis (Diot et al., 2014) reveals that the shape of the bands varies from linear to concentric geometries (Fig. 2). However, while potential mechanisms of material transfer recorded by the banded terrain has been elaborated in our previous paper (Diot et al., 2014), the stratigraphic relationship to the neighboring domains has not yet been elaborated upon, which is the scope of this paper. In doing so, we aim to understand better the geomorphic evolution of the deepest region of Hellas within a larger temporal and spatial context.

Here, we investigate the geomorphological assemblage of terrains situated in the northwest interior of Hellas in association with the banded terrain. This is accomplished through a possible reconstruction of the history of erosion, deposition and material transport, which is recorded by the landscape of Hellas. We use both newly-acquired and currently available datasets to determine the cross-cutting relationships between the geomorphic domains in the northwest interior of Hellas basin paying close attention to the contacts between the banded terrain and neighboring domains. In section 2, we describe the geological setting. In section 3, we provide information on the data sets used and in section 4 we present our observations and interpretations. Finally in section 5, we discuss the evolution of the northwest interior of Hellas from the interpretations of our observations and the possible formation mechanism of the investigated domains.

\section{Geological setting}

Hellas basin (centered at $40^{\circ} \mathrm{S}, 68^{\circ} \mathrm{E}$ ) was formed through a giant oblique impact $\sim 4 \mathrm{Ga}$ ago (Leonard and Tanaka, 1993; Tanaka and Leonard, 1995; Werner et al., 2008). The basin is 
$\sim 2,300 \mathrm{~km}$-long, $\sim 1,500 \mathrm{~km}$-wide and more than $7 \mathrm{~km}$-deep with respect to the elevation reference datum (Smith et al., 1999) making it the deepest and one of the largest depressions on Mars. Consequently, it has been a major trap for sedimentary deposits and for eroded material from the surrounding highlands (e.g. Tanaka and Leonard, 1995; Moore and Wilhelms, 2001; Crown et al., 2005; Bandfield, 2008; Wilson et al., 2010).

In the northern part of the basin, sediments appear to have been supplied through a wide network of channels (Wilson et al., 2010) as indicated by the presence of fan deposits (Moore and Howard, 2005; Wilson et al., 2010). These observations have been invoked by a number of studies as evidence for a large paleo-lake within Hellas (e.g., Cabrol and Grin, 2010; Haberle et al., 2001; Moore and Wilhelms, 2001). Most of the channels probably date to the Noachian-Hesperian boundary (Fassett and Head, 2008; Wilson et al., 2010). Layered deposits of a possible subaqueous origin (Ansan et al., 2011) and hydrated minerals such as phyllosilicates and hydrated silica have been identified in Noachian-aged craters located north of Hellas (e.g., Malin and Edgett, 2000; Mest and Crown, 2005; Bandfield et al., 2008, 2013a; Crown et al., 2010; Wilson et al., 2010; Ansan et al., 2011; Fortezzo and Skinner, 2013; Chuang et al., 2015).

Geomorphic studies of the eastern part of Hellas reveal the presence of fine-grained-layered material at the eastern boundary of a large volatile-rich depositional shelf, and the occurrence of multiple channels that extend toward the basin similarly suggesting a deposition within a paleo-lake (Crown et al., 2005; Bleamaster and Crown, 2010). These observations point to a complex history of erosion and deposition in an aqueous environment during the Late Noachian- Early Hesperian (e.g. Malin and Edgett, 2000; Moore and Wilhelms, 2001; Mest and Crown, 2006; Mest et al., 2010; Wilson et al., 2010). 
The northern and eastern flanks of the basin host multiple viscous flow features. These features include small and young (Late Amazonian) ice-rich flow lobes located on slopes (e.g. Milliken et al., 2003; Berman et al., 2009; Head et al., 2005; Hubbard et al., 2011), and larger, and older (Early Amazonian), lobate debris aprons surrounding mounds, which were interpreted to be analogous to terrestrial debris-covered glaciers (e.g. Squyres, 1979; Mangold and Allemand, 2001; Mangold, 2003; Pierce and Crown, 2003; Berman et al., 2009 and 2015).

With regard to the NW interior of Hellas, which is our main study region, recent geologic maps (e.g. Moore and Wilhelms, 2001) display four major domains: (i) a western band referred to as the reticulate terrain, (ii) a central plateau named the Alpheus Colles (ACP), (iii) widespread plains material surrounding the plateau, and (iv) honeycomb terrain. According to Moore and Wilhelms (2001), the geological and geomorphic evolution of the region is as follows (from the oldest to the youngest): the formation of the ACP dated to the Lower Hesperian via crater counting (Tanaka and Leonard, 1995; Leonard and Tanaka, 2001), the reticulate terrain, the plains material where the emplacement has been dated to Middle to Late Hesperian (Leonard and Tanaka, 2001), and finally the formation of the honeycomb terrain. More recently, high-resolution data allowed the mapping (Figs. 1A) of an additional geomorphologic domain dubbed "banded terrain” (Diot et al., 2014).

CTX and HiRISE images (see section 3 datasets and methods) reveal that the NW interior of Hellas is largely covered by the banded terrain (Fig. 1A; Diot et al., 2014). This domain has been dated to the Amazonian and displays a sinuous and smooth surface texture, suggesting that the material has been displaced by a viscous flow. The domain consists of juxtapositions of bands (3-15 km-long, $\sim 0.3 \mathrm{~km}$-wide) separated by narrow inter-bands depressions ( $65 \mathrm{~m}$ wide and at least $10 \mathrm{~m}$-deep). The surfaces of the bands display features such as fractured mounds, polygons and sublimation landforms (e.g. progressive blocky degradation), which 
may have formed in a periglacial environment (Diot et al., 2014). The banded terrain is in contact with two main domains of Hellas: the ACP to the south and the honeycomb terrain to the north (Fig. 1A). Overall, the banded terrain is present in a trough close to the NW edge of the ACP and in local places on the plateau (Fig. 1A).

\section{Datasets and methods}

The geomorphological investigation was carried out using: (i) the datasets from the Mars Orbiter Laser Altimeter (MOLA; Smith et al, 2001) onboard the Mars Global Surveyor, (ii) the Thermal Emission Imaging System camera (THEMIS; Christensen et al., 1999 and 2004; Edwards et al., 2011) on Mars Odyssey spacecraft, (iii) the Context Camera (CTX; Malin et al, 2007), and (iv) the High Resolution Imaging Science Experiment (HiRISE; McEwen et al., 2007), which are both onboard on the NASA's Mars Reconnaissance Orbiter. MOLA (468 m/pixel in resolution) provides an elevation map in a simple cylindrical projection of the near-entire surface of Mars. This map, combined with the THEMIS daytime infrared map (100 m/pixel in resolution) in the GIS environment JMARS (http://jmars.asu.edu; Gorelick et al., 2003), was used as a background for mapping. CTX typically obtains $30 \mathrm{~km}$-wide and 40 $\mathrm{km}$-long images with a resolution of $\sim 6 \mathrm{~m} /$ pixel. We used this dataset to trace the spatial extent of the different domains, and to characterize the surface texture of the different domains and their geometric relationships. The HiRISE camera has a lower spatial coverage yet offers a high spatial resolution of $25-50 \mathrm{~cm} /$ pixel, which we used for detailed investigations of cross-cutting relationships at the domain boundaries, and small-scale morphologic features thereof.

The geomorphological map of the NW of Hellas (Fig. 1A) was produced using JMARS. The identification of the domains relied mainly on their textures (rough, hummocky, smooth etc.) 
observed on high-resolution CTX and HiRISE images and their relative elevation on the THEMIS day-time underlying a MOLA colors map (where colors denote different elevation ranges). We thus used color differences between domains to delineate the boundaries separating them. The boundaries of the different domains were drafted using colored polylines of connected sequences of points.

We also created a $2 \mathrm{~m} /$ pixel HiRISE stereo Digital Terrain Model (DTM) built from the HiRISE image pair ESP_024936_1435 and ESP_033494_1435, using the commercial software SOCET SET from BAE Systems and the freely-available software Integrated Software for Imagers and Spectrometer (ISIS) from the United States Geological Survey (USGS), and utilizing previous methods (Kirk et al., 2008). Our HiRISE DTM was produced with vertical control relative to MOLA elevations. Using previous estimates (Kirk et al., 2003 and 2008), we determined a vertical accuracy of $0.271 \mathrm{~m}$. This DTM was used to generate the slope and relief maps of the reticulate terrain 2 presented in the section 4.3 within the GIS environment ArcGIS 10.1. ArcGIS (http://www.esri.com/software/arcgis) allows the combination of multiple datasets including elevation, slope patterns, volumes, relief, aspect ratios, etc. We identified the relief as the elevation difference between the highest point (representing the surface of the ridges) and the lowest point (representing the bottom of the depressions; Ahnert, 1984) within $400 \mathrm{~m} \times 400 \mathrm{~m}$ roving windows (Grohmann and Riccomini, 2009), which move horizontally on the HiRISE DTM. We have chosen a $400 \mathrm{~m} \times$ $400 \mathrm{~m}$-sized roving window because the polygonal structures of the reticulate terrain 2 (section 4.3) are approximately within this size range, which can help to gain insight on the geometry and mechanism of formation of this domain.

Finally, we derived thermal inertia maps ( 100 m/pixel) from THEMIS predawn band 9 $(12.57 \mu \mathrm{m})$ brightness temperature images using the thermal model of Putzig and Mellon (2007) and implemented in the "jENVI" software suite 
(http://arsia.gg.utk.edu/ utmars/jenvi/) (see Chojnacki et al. (2014) for a more detailed description of our methodology). Thermal inertia is a key surface property controlling diurnal and seasonal temperature variations and yields insight into the physical properties (e.g., grain size, degree of induration) of the martian near-surface (Putzig and Mellon, 2007). Although thermal inertia is largely controlled by particle size, it is also influenced by other factors (e.g., degree of induration, reduced pore space) (Mellon et al., 2000; Fergason et al., 2006b; Putzig and Mellon, 2007; Piqueux and Christensen, 2009), thus making interpretations of values generally non-unique (e.g. Christensen, 1986). This ambiguity is particularly the case for regions with high concentrations of dust on the surface, which is occasionally the case in Hellas Basin. To partially mitigate this issue, we preferentially selected THEMIS data of banded terrain locations with low dust coverage as estimated by the dust cover index from thermal emission spectroscopy (Ruff and Christensen, 2002). The thermal inertia values obtained during this study are shown in Table 1.

\section{Observations and Interpretations}

In this section, we built up on previous (e.g. Tanaka and Leonard, 1995; Moore and Wilhelms, 2001; Bernhardt et al., 2015) descriptions of the different domains including the Alpheus Colles Plateau (ACP), plain deposits, reticulate and honeycomb terrains emphasizing their textures (rough, hummocky, smooth etc.) and their fine-scale morphology, which we have discerned using the new datasets (e.g., HiRISE). We also characterize the contacts between the domains and the recently identified banded terrain (Diot et al., 2014). Fig. 1C shows the location of the figures presented in the following sections and sub-sections. 


\subsection{The banded terrain}

The banded terrain is characterized by a common morphology consisting of an alternation of sinuous bands and inter-bands displaying a variety of shapes including linear, concentric and lobate bands (Fig. 2). Finer-scale observations carried out using HiRISE images reveal the presence of multiple boulders on the surface of the bands (Fig. 3). These boulders have diameters in the range of 1 to $8 \mathrm{~m}$, and they are clustered in multiple places (Fig. 3A). Furthermore, fresh impact craters are surrounded by halos of similar boulders more or less symmetric around the craters (Fig. 3B). Where the halo displays an asymmetric shape, the number density and the size of the boulders decrease away from the crater (Fig. 3B). In addition, multiple rockfall deposits initiating from the bands' boundaries are observed in the banded terrain (Fig. 4). The size of the falling blocks ranges between 1 and $10 \mathrm{~m}$.

Another notable feature is located in the western part of the banded terrain area where we observe a tongue-shaped pattern $\sim 3 \mathrm{~km}$-long and $\sim 0.5 \mathrm{~km}$-wide (Fig. 5), which resembles features related to viscous flow features (VFFs, Milliken, et al., 2003; Souness et al., 2012; Hubbard et al., 2014). This tongue-shaped surface pattern is located $\sim 40^{\circ} \mathrm{S}$, which falls within the range of latitudes $\left(30^{\circ}-60^{\circ}\right.$ in both hemisphere) of VFFs (e.g. Milliken et al., 2003; Souness et al., 2012), yet is located at an elevation of $-6620 \mathrm{~m}$, which is much lower than the mean elevation $(+885 \mathrm{~m})$ of the analogous structures (Souness et al., 2012). The average MOLA slope of this feature is approximately $2^{\circ}$ trending southward. This poleward aspect is consistent with observations made for the VFFs (e.g. Milliken et al., 2003; Berman et al., 2009; Souness et al., 2012). The morphology of this feature (Fig. 5) is consistent with that of VFFs as defined by Souness et al. (2012). Namely, (i) it has a smoother surface than the surrounding landscape (Fig. 5A); (ii) it displays stripes or lineations on the lateral margins as well as frontal ridges indicative of a down-slope flow (Figs. 5A and C); (iii) it has a length to 
width ratio $>1$; and (iv) it has a discernable closed terminus and an evasive head (Figs. 5A and 5C). In addition, polygonal fractures located at the termination and multiple boulders at the evasive head are well visible (Figs. 5B and D) and similar to those observed on the surfaces of VFFs (e.g. Milliken et al., 2003; Hubbard et al., 2014).

The thermal inertia of the banded terrain (Table 1) ranges between 300 and $450 \mathrm{Jm}^{-2} \mathrm{~K}^{-1} \mathrm{~s}^{-1 / 2}$ (hereafter referred to as thermal inertia units [tiu]). The bands typically have higher values (around 400-450 tiu), while the thermal inertia in the lower-lying inter-bands varies between 300 and 380 tiu. These lower values most likely reflect the presence of fine- to coarse-grained sediment consistent with the aeolian mega-ripples within the inter-bands as visible in HiRISE images (Fig. 6A). Additionally, we attribute part of depressed thermal inertia values detected in the inter-bands to an enhanced surface dust, possibly caused by the $>10$ m-high elevation difference between the bands and inter-bands (Diot et al., 2014). Although low, the range (300-450 tiu) of thermal inertia of the banded terrain is significantly higher than that of dust (<120 tiu), which indicates a relatively consolidated or cemented surface with a partial coating of fine dust.

The elevation of the initiation points of the bands varies between $-7.4 \mathrm{~km}$ and $-5.6 \mathrm{~km}$ (average $\sim-6 \mathrm{~km}$ ). Locally, we observe a detachment of the bands from the NW boundary of the central ACP (Fig. 6B). These structures may have played a significant role in the shaping of the NW ACP's margin. Diot et al. (2014) interpreted the NW edge of the ACP as an erosive boundary. In addition, multiple bands are located on the top of the ACP. Therefore, we anticipate that the banded terrain formed after the emplacement of the ACP and that the motion of the material resulted in the erosion of the NW part of the plateau.

North of the banded terrain lies the honeycomb terrain, which consists of a set of geomorphic cells organized in a polygonal pattern (e.g. Moore and Wilhelms, 2001). The contact between 
these two geomorphologic domains appears to be complex and at times ambiguous. Close to, or in contact with the banded terrain, the interior of the cells displays infills that appear morphologically similar to that of the banded terrain, in particular the linear bands (Fig. 7A1). Thus, we conclude that the banded terrain deposits overlap the honeycomb cells and thereby post-date the formation of the honeycomb terrain. Further details concerning the geometric relationships between the banded and honeycomb terrains are provided in section 4.5 .

\subsection{The Alpheus Colles plateau (ACP)}

The ACP (Fig. 1A) is a large $\left(\sim 750,000 \mathrm{~km}^{2}\right)$ domain situated almost at the center of Hellas basin in an elevation range of $-7 \mathrm{~km}$ to $-6.2 \mathrm{~km}$ with an average of $\sim-6.5 \mathrm{~km}$. Moore and Wilhelms (2001) described this domain as a thick multilayered deposit characterized by knobs and hummocks. In CTX images, the ACP appears to be composed of a belt of chaotic terrain in the NW part (Fig. 8A) and a relatively smoother central part (Fig. 8B). The chaotic part is made up of multiple, relatively large partially elongated knobs or hills (Fig. 8A). These knobs consist of a stack of multiple dark and sometimes white layers (see white arrows and sketch in Fig. 8A). These observations are consistent with the ones by Moore and Wilhelms (2001) who recognized multiple layers on Viking images. The surface texture of the central part hosts multiple smooth lobate shapes (Fig. 8B) that drape over the floor of the ACP. We interpret this texture to have formed through a remobilization of an ice-rich mantle that was originally deposited during periods of high obliquity. In the same area, Bernhardt et al. (2015) mapped a layer of ice-rich mantle material on the top of the ACP. Moreover, the texture and shape of the lobate features (Fig. 8B) is analogous to lobate debris aprons, which 
have also been considered to have an ice-related origin (e.g. Mangold and Allemand, 2001; Pierce and Crown, 2003; Berman et al., 2015).

Thermal inertia data (Table 1) reveal low values ( 220 tiu) for the ACP pointing to the presence of a fine-grained surface material such as silt or fine sand, but not dust $(<60 \mu \mathrm{m})$ (Putzig and Mellon, 2007). Such values of thermal inertia are similar to the lowest values (4$610^{-3} \mathrm{cal} \mathrm{cm}^{-2} \mathrm{~s}^{1 / 2} / \mathrm{K}$, equivalent to $168-250$ tiu) obtained by Moore and Edgett (1993) for central Hellas using (IRTM), and similarly interpreted by them to represent fine sands.

The occurrence of large degraded and/or buried craters (Moore and Wilhelms, 2001) indicates that the plateau has experienced a long erosional history and is considered to be the oldest (Lower Hesperian) domain in the basin's interior (Tanaka and Leonard, 1995; Leonard and Tanaka, 2001; Moore and Wilhelms, 2001; Bernhardt et al., 2015).

\subsection{The plain deposits}

The northwestern interior part of the basin is covered by a widespread $\left(\sim 142,000 \mathrm{~km}^{2}\right)$ material with a wavy-looking surface texture (at THEMIS images scale), situated at an elevation range of $-7.2 \mathrm{~km}$ to $-6.6 \mathrm{~km}$ (average $~-7 \mathrm{~km}$ ). This domain has been identified as plains-forming material in previous studies (e.g. Tanaka and Leonard, 1995; Leonard and Tanaka, 2001; and Moore and Wilhelms, 2007; Bernhardt et al., 2015). Two different geomorphologic domains of plain deposits can be distinguished on the THEMIS day-time imagery with MOLA colors map (Fig. 1A): a $~ 124,000 \mathrm{~km}^{2}$-wide "plain deposit 1" domain (P1, represented by a gray-violet color indicative of an elevation of $\sim-6.940 \mathrm{~km}$ in Fig. 1A), which is embayed by a smaller $\sim 18,000 \mathrm{~km}^{2}$-wide "plain deposit 2" domain (P2, represented by a dark violet color indicative of a lower elevation of $\sim-6.970 \mathrm{~km}$ ). A slight difference in 
thermal inertia (Table 1) is observed between P1 (200-260 tiu) and P2 (260-300 tiu). Such values of thermal inertia suggest the presence of a fine- grained material for P1 and P2 as silt or fine sand, similar to the ACP (Putzig and Mellon, 2007). At the scale of the THEMIS daytime data with MOLA colors map, the P1 and P2 domains show a relatively smooth and wavy featureless surface (Fig. 1A). CTX images show that the P1 domain is characterized by the presence of local round-shaped knobs whereas P2 displays a widespread and relatively smooth surface (Figs. 9 and 10A1). Accordingly, the surface of P1 appears to be more degraded than that of P2. However, using HiRISE images, the surface of P2 appears to be pitted (Figs. 10B, 10C and 11). The pits are 1-8 m-wide and have an angular shape. An uneven and sinuous morphological transition (Figs. 9A1 and A2) between P1 and P2 is clearly observable on CTX images. Along this contact (contact underlined by white arrows on Figs. 9A1, 9A2 and 9B), the shadow derived from the boundary of P2 is observed on P1, suggesting that P2 overlies P1. Moreover, we observe that a smooth material analogous to P1 seems to overlap the ACP in the eastern part of Hellas. This observation is consistent with the identification by Moore and Whilelms (2001) of a plain forming material overlapping the central plateau in the eastern interior of Hellas (Fig. S1 in the supplementary material). Moreover, the geomorphologic mapping (Fig. 1A) and geometric relationships show that P2 is in contact with the reticulate and honeycomb terrains. Indeed, P2 appears to be intermixed with some structures of the honeycomb and reticulate terrains. The details of the geometric relationships between $\mathrm{P} 2$ and these two domains are presented in the following sections.

\subsection{The reticulate terrain}

Earlier and recent studies (e.g. Moore and Wilhelms, 2001 and 2007; Wilson et al., 2010; Bernhardt et al., 2015) of the western interior of Hellas have mapped one curved band of 
reticulate terrain named here RT1 (Figs. 1A, 10A1 and 10A2), which consists of ridges organized in a polygonal pattern and separated by flat depressions that host small sinuous ridges in some places. Based on the cross-cutting relationships, the size and the surface texture, we identified and mapped multiple outcrops of a second geomorphologic domain of reticulate terrain (RT2), situated in the northwest interior of Hellas (Figs. 1A, 10B, 10C, 11, 12 and 13). Similarly to RT1, the RT2 domain can be characterized by the occurrence of ridges that are interconnected in a polygonal pattern and separated by relatively flat depressions (Figs. 10B, 10C, 11, 12 and 13). However, the RT2 domain differs from RT1 in terms of elevation and size-scale. RT1 depressions (Figs. 10A1 and 10A2), located at elevations ranging from $-5.9 \mathrm{~km}$ to $-5.6 \mathrm{~km}$, are larger (1-2 km across) than RT2 depressions (Figs. 10B, 10C, 11, 12 and 13), which in turn are located at a lower elevation of $\sim-7.2 \mathrm{~km}$ and have cross-sectional widths that range between $250 \mathrm{~m}$ and $1 \mathrm{~km}$. Similarly, the RT1 ridges are larger ( $200 \mathrm{~m}$ to $1 \mathrm{~km}$ ) than the RT2 ones, which fall in the range of $\sim 20-100 \mathrm{~m}$. In addition, the HiRISE images reveal that while RT1 and RT2 ridges show a pitted surface with angular boulders $\sim 2 \mathrm{~m}$ in diameter, the floor of the depressions is flat and relatively smooth (Figs. 10A1, 10B and 10C, 11). In one location, a network of faults oriented NW-SE is observed (Figs. 10B and 10C). The faults are between $65 \mathrm{~m}$ and $730 \mathrm{~m}$ long (with an average of $\sim 230 \mathrm{~m}$ ), and the spacing between them is irregular. The presence of triangular morphologies on the top suggests a vertical offset up to the NE.

We used a HiRISE DTM to compute the slope and the relief of the RT2 domain (Figs. 12 and 13). The average slope near the ridges ranges between $30^{\circ}$ and $50^{\circ}$, while the floors of the depressions are $\leq 2^{\circ}$ (Fig. 12B). Furthermore, relief profiles (profiles A-A' and B-B' on Fig. 13) show that the depressions between the ridges are associated with peaks of relief that range between 15 and $20 \mathrm{~m}$ (Fig. 13). Unfortunately, a similar analysis for the RT1 domain is not possible due to the lack of a similar DTM. 
In addition to the morphometric differences, the cross-cutting relationships are also different for RT1 and RT2. Indeed, in the western part of Hellas, P1 overlies the RT1 domain (Moore and Wilhelms, 2001; Figs. 10A1 and 10A2). Therefore P1, and, by extension, P2 appear to post-date the formation of RT1. In the northwest Hellas interior, the multiple patches of the RT2 domain suggest that RT2 might have exhibited a larger spatial coverage in the past. Moreover, HiRISE images show the same P2's pitted surface with boulders 1-8 $\mathrm{m}$ wide grading into the ridges of the RT2 (Figs. 10B, 10C, 11A, 11B and 11C). Unlike RT1, the RT2 domain is not overlain by $\mathrm{P} 1$.

\subsection{The honeycomb terrain}

The honeycomb terrain is extensive in the NW interior of Hellas (Fig. 1A) and located in a range of elevation between $-7.4 \mathrm{~km}$ and $-7 \mathrm{~km}$ (average $\sim-7.2 \mathrm{~km}$ ). Moore and Wilhelms (2001) named this domain in their map "honeycomb material" and described it as a belt circumferential to the ACP of elliptical and polygonal rimmed shapes analogous to "biological cells" (Figs. 7A1, 7A2, 14A and 14B1). These shapes have diameters 3-15 km wide (e.g. Leonard and Tanaka, 2001; Moore and Wilhelms, 2001 and 2007; Wilson et al., 2010) and display an overall E-W orientation. CTX images reveal that the shape of the honeycomb "cells" varies from relatively concentric to elongated (Figs. 7A1 and 7B) without a distinct pattern. Possible layer-like structures can be observed in some cells (see white arrows on Fig. 7A2). Thermal inertia data (Table 1) reveal values of 250-350 tiu with peaks around 400 tiu for the rims of the "cells", which are consistent with the values reported in Moore and Edgett (1993) for the center of Hellas. This relatively low range of values is indicative of a cemented sand-sized material (e.g. Putzig and Mellon, 2007). The slight 
difference in thermal inertia between the interior and the rim of the cells is explained by the preferential accumulation of fine to coarse grained material in topographic depressions.

The honeycomb terrain appears to be enclosed by the P2 geomorphologic domain (Fig. 14A). Indeed, using CTX images, we observe that some areas of P2 form the edges of the honeycomb cells. Likewise, ridges of the RT2 domain are twisted and curved in contact with honeycomb cells (Fig. 14). We identified P2 and RT2 to be ubiquitous in the entire NW interior region of Hellas below the honeycomb terrain (Fig. 14). In addition, HiRISE and CTX images reveal that some honeycomb structures display similar surface textures to the linear bands of the banded terrain (Fig. 7A1), while other cells have a relatively smooth to knobby surface where they are farther away from the banded terrain (Fig. 7B).

\section{Discussion}

The combination of previous studies (e.g. Tanaka and Leonard, 1995; Moore and Wilhelms, 2001 and 2007; Wilson et al., 2010; Bernhardt et al., 2015) with our new observations of the assemblage of terrains in association with the banded terrain enables us to gain an improved understanding of the geologic history of the NW interior of Hellas. In the following sections, we discuss the complex cross-cutting relationships of the terrains, and propose possible origins for the different geomorphologic domains.

\subsection{Evolution of the northwestern interior of Hellas}

The relative correlation (Fig. 15) of the different geomorphologic domains of Hellas that emerges from this study suggests that the main period of deposition and reworking in the NW interior of Hellas basin spanned the period between the Late Noachian- Early Hesperian and 
Early Amazonian, consistent with previous studies (Tanaka and Leonard, 1995; Moore and Wilhelms, 2001 and 2007; Diot et al., 2014; Bernhardt et al., 2015). However, because the surface of our study area has experienced erosion over a large part ( 4 Ga) of the Martian history, a precise dating of some of the domains is not possible. The surfaces of P1, P2, RT1 and RT2 display differences in the degree of erosion (Figs. 9 and 11). Indeed, P1 and P2 display smooth and knobby areas RT1 and RT2 present relatively rough-pitted ridges and smooth interiors. Due to this, the definition of a representative surficial texture for these domains is not possible. Concerning the RT2 domain, the narrow spatial extent consists of an additional issue for crater counting (e.g. Tanaka et al., 2014; Bernhardt et al., 2015). These points also result in atypical crater populations and non-representative age.

As such the correlation (Fig. 15) between the geomorphologic domains was essentially established based on the corresponding cross-cutting relationships described in section 4 . Observations (e.g. Knob belts and pitted texture, buried craters) of areas of deep erosion (Fig. 8) presented in section 4.2 in combination with previous estimates of a Late Noachian-Early Hesperian age of emplacement for ACP (e.g. Tanaka and Leonard, 1995; Bernhardt et al., 2015) suggest that this domain is the oldest of Hellas. Likewise, cross-cutting relationships between the domains allow a refinement of the geomorphologic evolution of the NW Hellas. The major observations are (section 4): (i) P2 overlaps P1 (Fig. 9) ; (ii) P1 and necessary P2 cover some RT1 depressions (Figs. 10A1 and 10A2); (iii) P1 and necessary P2 are on the top of ACP in the eastern Hellas (Fig. S1 in supplementary material); (iv) P2 and RT2 ridges are deformed (twisted and curved) by the cells of the honeycomb terrain (Fig. 14). In addition, (v) spatial extension of RT2's ridges within P2 (Figs. 11B and 11C) and (vi) observations of boulders on the floor of RT2 as relic of P2 (Figs. 11A, 11B and 11C) suggest that RT2 formed through the erosion of $\mathrm{P} 2$. This is additionally supported by the concave shape and the multiple RT2 outcrops that are typical of an erosional landscape. Finally, (vii) the banded 
material observed in some honeycomb cells (Fig. 7A1) may be remnants of a banded terrain infill. Consequently, the geomorphological history can be divided into three major episodes (Fig. 15): 1) emplacement of the ACP, 2) formation of RT1 followed by the plain deposits (P1 and P2) followed shortly by the formation of the RT2 and the honeycomb terrain domains, and 3) the formation of the banded terrain, structurally linked to the ACP. Thus the Amazonian-aged banded terrain (Diot et al., 2014) represents the last major depositional event in the NW interior of Hellas.

During the Amazonian, the geomorphic modifications have been mainly controlled by wind erosion, cryoturbation of the surface and remobilization of an ice-rich mantle deposit (Figs. 5 and $8 \mathrm{~B})$. We base this interpretation on the absence of any large domains post-dating or overlying the banded terrain. The observation of mega-ripples or small dunes with sharp crests in the inter-bands and triangular-shaped landforms on the top of the faults in the RT2 (Figs. 6A, 10B and 10C) is consistent with the occurrence of recent aeolian deposits and related erosional features. The tips of the triangular-shaped landforms, inferred to be caused by wind erosion, indicate a mostly SW-NE wind trend, which is consistent with winddirections in NW Hellas as modeled by Howard et al. (2012). However, the lack of large dune fields and other major aeolian structures in this part of the basin suggests that wind erosion has been limited in extent (Howard et al., 2012). Likewise, the absence of aeolian features can also be due to the relative absence of readably mobilized sand sizes (very fine to fine sand). This latter interpretation may be supported by the thermal inertia values $(300-$ 450 tiu) obtained for the NW interior of Hellas, which are consistent with coarse grained sediment (very coarse sand to cobbles; Piqueux and Christensen, 2009). It should be noted that these particle sizes are larger than the $\sim 1 \mu \mathrm{m}$-sized particle, which are the most-likely mobilized grains under present martian conditions (e.g. Read and Lewis, 2004). 
The banded terrain is located in the latitudinal band $\left(35^{\circ}-55^{\circ}\right)$ where Amazonian periglacial landforms have been extensively mapped on Mars (Squyres, 1979; Squyres and Carr, 1986; Head et al., 2005; Mangold, 2003; Milliken et al., 2003). Thus, the erosional features present on the surface of the bands including clusters of boulders, rockfalls, and periglacial features (Diot et al., 2014) suggest a combination of several periglacial erosional processes (Matsuoka, 1995; Head et al., 2011; Heldmann et al., 2013), cryoturbation and wind-induced abrasion, consistent with observations in terrestrial periglacial environments e.g., in the McMurdo Dry Valley, USA for example (Hall and Andre, 2001; Heldmann et al., 2013). For instance, the rockfalls and the clusters of boulders (Fig. 4) could have developed in response to mechanical weathering such as thermal cracking or sublimation processes. These features occur relatively often on the flanks of mountains on Earth (Giani, 1992; Valbuzzi et al., 2014). A possible initiation mechanism of these rockfalls is fracturing of rocks due to frost weathering and thermal contraction of the ground (Giani, 1992).

\subsection{Possible origins of the domains}

\subsubsection{The plain deposits}

Various hypotheses including volcanic and aqueous (e.g. Moore and Wilhelms, 2001; Bernhardt et al., 2015) origins for the widespread plain deposits (P1 and P2) have been previously proposed and are discussed in the following section. Table 2 summarizes the various origin hypotheses for each domain.

The smooth surfaces identified for the P1 and P2 domains could have originated through deposition of suspended material in a lake or may have been produced by the discharge of material from rivers, for instance through Dao or Harmakhis canyons (Moore and Wilhelms, 
2001). We suggest this mainly because lacustrine deposits are mostly characterized by finegrained and stratified deposits. Likewise, aqueous environments on Earth, but also volcanic settings are known to form analogous widespread relatively smooth surfaces. The relatively low thermal inertia (200-300 tiu) acquired for P2 and P1 may favor this hypothesis, although airfall dust may have affected these measurements. Recently, Bandfield et al., (2008 and 2013a) have detected amorphous hydrated silica in the western interior of Hellas close to P2 and P1. The formation of these minerals requires a relatively large amount of water (Bandfield et al., 2013a). Due to the lack of other aqueous quartz, the amorphous form of the hydrated silica and the sporadic spatial extent, Bandfield et al., (2013a) proposed a local source of water confined to the west of Hellas to form these minerals. It is unlikely that the $\mathrm{P} 1$ and P2 domains, considering their large spatial coverage $\left(\sim 142,000 \mathrm{~km}^{2}\right)$, would have been deposited by an ephemeral and spatially localized water body. Moreover, we do not observe light-toned layering or a stratified pattern within the P2 and P1 domains as observed by Ansan et al., (2011) for the lacustrine deposits in the Terby crater. Finally, Crown et al. (2005) noted a lack of fluvial landforms, which is inconsistent with the interpretation of large-scale catastrophic flooding as formation mechanism for the plain deposits (at least P2) in the eastern part of Hellas. Therefore, further investigations and additional HiRISE coverage are necessary to validate or reject the hypothesis of a formation via suspension in a lake.

Alternatively, effusive low viscosity lava flows such as the ones of the Etna or the Hawaiian volcanoes (Hon. et al, 1994; Moore and Wilhelms, 2001; Bernhardt et al., 2015) can form large basaltic-lava sheets. However, the relatively low thermal inertia (200-300 tiu) obtained for the P2 and P1 domains is inconsistent with basaltic lavas, which typically reach 1,200 tiu (e.g. Fergason et al., 2006a; Putzig and Mellon, 2007). A possible explanation for this large difference is a post-depositional fragmentation of the material through physical weathering, 
where the resulting debris may have a thermal inertia of $<600$ tiu (Bandfield et al., 2013b). We note that such an origin for P1 and P2 would have further implications for interpreting their structural and cross-cutting relationships with the neighboring honeycomb and the RT2 domains presented in section 4.3 and 4.4. In fact, despite their larger size (two to four orders of magnitude), the surface texture of the honeycomb and RT2 domains are visually similar to the surface in the northern Byers Peninsula in Antarctica (Moura et al., 2012), where multiple freeze-thaw cycles have resulted in the formation of a patterned surface texture of volcanic tuffs. However, the large distances to the closest observable volcanic source regions, Amphitrites and Peneus Paterae ( 1,400 km to the South) and Hadriacus Mons $(\sim 2,000 \mathrm{~km}$ to the East) challenges the volcanic origin for the plain deposits.

Finally, formation of $\mathrm{P} 1$ and $\mathrm{P} 2$ through a combination of deposition, erosion and remobilization (periglacial processes, wind abrasion for example) of a relatively young icerich mantle deposit should be considered (e.g. Crown et al., 2005). Indeed, climatic models at the planetary scale (e.g. Haberle et al., 2003; Forget et al., 2006; Madeleine et al., 2014) showed that ice would accumulate in the region of Hellas during periods of high-obliquity. Consequently, ice mixed with dust might form a thick ice-rich mantle layer in the midlatitudes as in the case of Malea Planum close to Hellas basin (e.g. Willmes et al., 2012; Conway and Balme, 2014). Thermal inertia values of 200 tiu to 300 tiu, which are indicative of fine-grained materials on the P1 and P2 surfaces, are consistent with this interpretation.

\subsubsection{The Honeycomb terrain}

In the case of the honeycomb terrain, Moore and Wilhelms (2001) proposed a formation by soft-sediment deformation of waterlogged bottom sediment caused by the pressing of ice within an ice-covered lake (Lowe, 1975; Allen, 1982). The low thermal inertia values ( 400 
tiu) for this domain indicate the presence of a fine to coarse-grained partially consolidated material, which could have experienced soft-deformation. In addition, the lack of evidence for brittle deformation (fractures, faults, etc.) combined with observations of local intensive folding support the occurrence of soft or ductile deformation.

Based solely on the morphology of the honeycomb and RT2, a formation in response to the rise of diapirs driven by buoyancy effects of salt (Fig. 16A) or plutons could provide interesting viable alternatives (Mangold and Allemand, 2003; Leppänen et al., 2012; Bernhardt et al., 2015). In the case of the hypothesis of the magmatic diapirs (Mangold and Allemand, 2003; Lin, 2005), the general morphology of the honeycomb terrain (Fig. 7) displaying ridges (relative highs) and oval depressions (relative lows) resembling the Archean dome-and-basin structures (e.g. Bouhallier et al., 1995; Bloem et al., 1997; Chardon et al., 1998; Mangold and Allemand, 2003; Lin, 2005). Triangles of intensive folding between the oval shaped-plutons are observable in terrestrial Archean $(\sim 4 \mathrm{Ga})$ diapirs. The formation of these folds is related to the anatexis upon magma emplacement, where the heat of the rising magma results in the partial melting of the surrounding rocks. Such a mechanism could explain the observed inter-honeycomb's cells areas of ductile deformation. However, magmatic diapirism is commonly associated with large heat flows and intense deformation over broader scales of several kilometers (e.g. Choukroune et al., 1995; Nadin et al., 1995; Choukroune et al., 1997; Mège and Ernst, 2001). There is no evidence for tectonic deformation at that scale in the Hellas basin. Unfortunately, we do not have quantitative data about crustal heat flux or mineralogical assemblages indicative of high temperature conditions to properly address this hypothesis. Nevertheless, we consider that the lack of evidence for large-scale deformation in Hellas and the implication of very high heat flow challenge this magmatic diapirism hypothesis as mechanism for the formation of the honeycomb terrain. 
Another hypothesis to consider is the salt diapirism. The rise of salt diapirs on Earth requires weakening (mostly fracturing and erosion) of the overburden surface (Turcotte and Schubert, 1982; Mangold and Allemand, 2003; Hudec and Jackson, 2007; Talbot et al., 2009), which is mainly accomplished in areas of active regional deformation (Vendeville and Jackson, 1992). However, in the honeycomb area, we observe that the material between the honeycomb cells is mainly folded and only few fractures can be identified. In addition, markers of intense regional deformation are lacking in Hellas basin. Salt diapirism is commonly associated with complex tectonic processes that can be divided in three stages: (i) "reactive", (ii) "active" and (iii) "passive" diapirism (e.g. Nelson et al., 1989; Vendeville and Jackson, 1992). The intense fracturing of the overburden surface enunciated above occurs in the "reactive" and "active" phases while no fractures and local subsidence are observed during the "passive" stage (e.g. Nelson, 1989; Vendeville and Jackson, 1992). Thus, reworking and erosion of the surface posterior to the rise of the salt via, for instance, periglacial processes or wind activity, could have removed part of the brittle structures, at least in our case. Accordingly, the honeycomb terrain could reflect the local subsidence of the "passive" stage only. Although we cannot fully address this question with the available data, we note that if such diapirism occurred in waterlogged bottom sediment within a lake, then it could explain the morphology and ductile deformation of the honeycomb and also the lack of clear signs of tectonism.

Finally, the ice diapirism hypothesis, proposed by Schenk and Jackson (1993, 2007) to explain the Cantaloupe terrain on Neptune's icy-moon Triton (Fig. 16B) could potentially explain the shape and texture of the honeycomb terrain. Despite their larger size $(\sim 40-50$ $\mathrm{km})$, the cells of the Cantaloupe terrain reveal a rough to hummocky interior with a smooth elevated outer annulus similar to the honeycomb cells. Likewise, the intercellular material of the Cantaloupe terrain is arranged as sigmoids (e.g. Schenk and Jackson, 1993, 2007) and folds analogous to the features in the honeycomb terrain. Finally, the cantaloupe cells display 
a spacing that is similar to that of the honeycomb cells. Schenk and Jackson $(1993,2007)$ suggested a formation through a vertical flow of an over-pressured ice buried below the surface. However we note that the similarities between the Cantaloupe and honeycomb terrains are probably only morphological since the chemical properties and rheology of the ice on Triton is not known. First, the composition of the Triton's ice is not well constrained and may be made up of water and nitrogen, which is probably the major component of Triton's surface (Schenk and Jackson, 1993, 2007). Second, at the very low surface temperature (30-40 K) (e.g. Tryka et al., 1993) of Triton, the rheology of water and nitrogen ice is unknown. Moreover, water ice diapirism has been suggested to explain the circular to elliptical morphology of some depressions at the surface of Jupiter's icy-moon Europa (e.g. Pappalardo et al., 1998; Rathbun et al., 1998). These features are 7-15 km in diameter, which is in the range of the honeycomb cells, and they are relatively regularly spaced. Pappalardo et al. (1998) proposed that these features are the manifestation of the rise of relatively warm water ice masses through the thick ice-rich surface of Europa. Although morphological differences exist between the features on Europa and the honeycomb cells (e.g. the absence of an outer elevated boundary for the depressions on Europa), the overall landscape of the Europa's fields of depressions do resemble the shape of the honeycomb terrain. It should be noted that the surface in the Hellas basin is not mainly composed of ice. Therefore, the surface manifestation of such ice diapirs is likely to be different than on Europa.

\subsubsection{Spatial extent of the banded terrain}

An extensive discussion about the mechanisms leading to the shape and surface texture of the banded terrain has already been presented by Diot et al., (2014). Here, we discuss the spatial 
relationships of the banded terrain with the domains that we have discussed in the previous chapters.

The cross-cutting relationships suggest that the origin of the banded terrain is structurally linked to the ACP. Likewise, the gradual contact between the honeycomb terrain and the banded terrain seems to reflect a northward progressive transition. In fact, previously reported mapping (Diot et al., 2014) shows that the concentric bands are generally located close to the honeycomb cells and display a global E-W orientation analogous to the honeycomb cells. In addition, Diot et al. (2014) suggested that the surface texture of the banded terrain formed in response to a northward-directed surficial viscous flow starting from the NW edge of the ACP. In this context, the observed E-W banded material within the honeycomb cells could have resulted from a deviation in flow direction as the banded terrain material hit the edges of the honeycomb cells. Thus the concentric bands could mask the presence of honeycomb cells that are filled by the viscous material of the banded flows. Further to the north, the honeycomb cells were apparently not completely filled with banded material as the corresponding material is only visible within the cells but not their margins (Fig. 7A1). Accordingly, the northernmost ( $40 \mathrm{~km}$ to $60 \mathrm{~km}$ far from the concentric bands) honeycomb cells displaying no banded material (Fig. 7B) represent the northern boundary of the banded terrain flow.

We conclude that the possible flow of the banded terrain could have covered the NW interior of Hellas to a large extent. Moreover, the ambiguous concentric bands may be the result of interactions between the flowing material and the buried topography of the honeycomb unit.

\section{Summary}


In this study we analyzed the geomorphological assemblage of several domains mapped in the NW interior of Hellas.

Seven domains have been identified within the basin: the banded terrain, the central plateau named Alpheus Colles, two plain deposits (P1 and P2 domains), the reticulate terrains (RT1 and RT2 domains), and the honeycomb terrain. The analysis of the geomorphology of these domains and their correlation combined with ages previously estimated by other studies reveals that the major period of deposition in the interior of Hellas basin spans the period between the Late Noachian and the Amazonian. The newly acquired CTX and HiRISE images enable us to subdivide the plain deposits and reticulate domains into two subdomains each: P1, P2 and RT1, RT2. Consequently, we propose the following sequence of formation (from the oldest to the youngest): Alpheus Colles plateau, RT1, P1 and P2, RT2, honeycomb terrain and banded terrain (Fig. 15). We note however that the possible gradual transition between the honeycomb and the banded terrain shows that the banded terrain flow may have covered a larger part of the NW interior of Hellas than observed today.

We do not observe significant surface alteration post-dating the formation of the banded terrain indicating a relatively low level of geologic activity during the Amazonian in the NW Hellas. The conspicuous erosional surface expressions in the form of clusters of boulders, rockfalls or periglacial structures at the bands' surface suggest the occurrence of erosive processes in cold desert environments modifying the landscape. We suggest that the history of the basin can be divided into three major episodes: 1) formation of the ACP, 2) formation of RT1 followed by the plain deposits (P1 and P2) followed shortly by the formation of the RT2 and the honeycomb terrain domains, and 3) the formation of the banded terrain, structurally linked to the ACP. This implies that whatever process formed the banded terrain is the most recent major depositional process that shaped the NW interior Hellas basin to a large extent. 
The newly-acquired thermal inertia data combined with the cross-cutting relationships allow the formulation of distinct hypotheses about the origins of formation of some of the domains. We tentatively favor an ice-rich volcanic debris or ice-dust mantle deposition during highobliquity phases for P1 and P2 and ice diapirism for the honeycomb domain. Thus, icerelated processes seem to have significantly shaped the interior of the basin during its past history. This study thus shows that the suite of erosional and depositional processes leads to a complex surface architecture that can only be deciphered if high-resolution images are available.

\section{Acknowledgments}

XD would like to thank the Center for Space and Habitability of the University of Bern for funding and supporting this study. MR EL-M, NT, and FS are supported by funds from the Swiss National Science Foundation (SNSF). The stereo DTM processing was carried out at the UK NASA RPIF at University College London. The authors would like to thank Luca Guallini for discussion and a review of the paper. The authors would like also to thank Daniel Mège and an anonymous reviewer for their constructive reviews, which improved the manuscript overall. 


\section{References}

Ahnert F., 1984. Local relief and the height limit of mountain ranges. American Journal of Science 284, 1035-1055.

Albee, A., 2002. The Mars Global Surveyor mission: description, status, and significant result. Highlights of Astronomy 12, 631-635.

Allen John, R., 1982. Sedimentary structures, their character and physical basis. Vol. 1, Elsevier.

Ansan, V., Mangold, N., Masson, P., Gailhardis, E. and Neukum, G., 2008. Topography of valley networks on Mars from Mars Express High Resolution Stereo Camera digital elevation models. Journal of Geophysical Research (Planets) 113, 7006.

Ansan, V., Loizeau, D., Mangold, N., Mouélic, S. L., Carter, J., Poulet, F., Dromart, G., Lucas, A., Bibring, J.-P., Gendrin, A., Gondet, B., Langevin, Y., Masson, P., Murchie, S., Mustard, J. and Neukum, G., 2011. Stratigraphy, mineralogy, and origin of layered deposits inside Terby crater, Mars. Icarus 211 (1), 273-304.

Bandfield, J. L., 2008. High-silica deposits of an aqueous origin in western Hellas basin, Mars. Geophysical Research Letters 35 (12).

Bandfield, J. L., Amador, E. S. and Thomas, N. H, 2013a. Extensive hydrated silica materials in western Hellas basin, Mars. Icarus 226 (2), 1489-1498.

Bandfield, J. L., Edwards, C. S., Montgomery, D. R. and Brand, B. D., 2013b. The dual nature of the martian crust: young lavas and old clastic materials. Icarus 222 (1), 188-199.

Berman, D. C., Crown, D. A. and Bleamaster, III, L.F., 2009. Degradation of mid-latitude craters on Mars. Icarus 200 (1), 77-95.

Berman, D. C., Crown. D. A. and Emily C. S. Joseph, 2015. Formation and mantling ages of lobate debris aprons on Mars: Insights from categorized crater counts. Planetary and Space Science (111), 83-99.

Bernhardt, H., Hiesinger, H., Ivanov, M. A., Ruesch, O., Erkeling, G., and Reiss, D., 2015. Photogeologic mapping and the geologic history of the Hellas basin floor, Mars. Icarus, doi:10.1016/j.icarus.2015.09.031.

Bleamaster, L.F., and Crown, D.A., 2010. Geologic Map of MTM -40277, -45277, -40272, and -45272 Quadrangles, Eastern Hellas Planitia region of Mars. U.S. Geological Survey Scientific Investigations Series Map 3096, scale 1:1,004,000.

Bloem, E. J., Dalstra, H. J., Ridley, J. R. and Groves, D. I., 1997. Granitoid diapirism during protracted tectonism in an Archaean granitoid-greenstone belt, Yilgarn Block, Western Australia. Precambrian Research 85, 147-171.

Bouhallier, H., Chardon, D. and Choukroune, P., 1995. Strain patterns in Archean dome-andbasin structures: the Dharwar craton (Karnataka, South India). Earth and Planetary Science Letters 135, 57-75.

Cabrol, N. A. and Grin, E. A., 2001. Composition of the drainage network on early Mars. Geomorphology 37, $269-287$.

Cabrol, N. A. and Grin, E. A., 2010. Searching for lakes on Mars: Four decades of exploration. Nathalie A. Cabrol and Edmond A. Grin. Lakes on Mars, Elsevier, Amsterdam, 1-29.

Carr, M, 1995. The martian drainage system and the origin of valley networks and fretted channels. Journal of Geophysical Research 100, 7479-7507.

Carr, M. and Chuang, F., 1997. Martian drainage densities. Journal of Geophysical Research 102, 9145-9152.

Carter, J., Poulet, F., Bibring, J.-P., Mangold, N. and Murchie, S., 2013. Hydrous minerals on Mars as seen by the CRISM and OMEGA imaging spectrometers: updated global view. 
Journal of Geophysical Research: Planets 118 (4), 831-858.

Chardon, D., Choukroune, P. and Jayananda, M., 1998. Sinking of the Dharwar basin (South India): implications for Archean tectonics. Precambrian Research 91, 15-39.

Christensen P. R., 1986. The spatial distribution of rocks on mars. Icarus 68: 217-238. DOI: 10.1016/0019-1035(86)90020-5.

Christensen, P. R., Jakosky, B. M., Kieffer, H. H., Malin, M., McSween, Jr., H. Y., Nealson, K., Mehall, G., Silverman, S. and Ferry, S., 1999. The Thermal Emission Imaging System, (THEMIS) Instrument for the 2001 Orbiter. Lunar and Planetary Science Conference, Abstract 1470.

Christensen, P. R., Bandfield, J. L., Bell III, J. F., Gorelick, N., Hamilton, V. E., Ivanov, A., Jakosky, B. M., Kieffer, H., Malin, M. and others, 2003. Morphology and composition of the surface of Mars: Mars Odyssey THEMIS results. Science 300, 2056.

Christensen, P. R., Jakosky, B., Kieffer, H., Malin, M., McSween, H. Y., Nealson, K., Mehall, G., Silverman, S., Ferry, S., Caplinger, M. and Ravine, M., 2004. The Thermal Emission Imaging System, (THEMIS) for the Mars 2001 Odyssey Mission. Space Science Reviews 110 (1-2), 85-130.

Chojnacki, M., Burr, D.M. and Moersch, J.E., 2014. Valles Marineris dune fields as compared with other martian populations: Diversity of dune compositions, morphologies, and thermophysical properties. Icarus 230, 151-161.

Choukroune, P., Bouhallier, H. and Arndt, N. T., 1995. Soft lithosphere during periods or Archean crustal growth or crustal reworking. Geological Society, London, Special publications 95, 67-86.

Choukroune, P., Ludden, J. N., Chardon, D., Calvert, A. J. and Bouhallier, H., 1997. Archean crustal growth and tectonic processes: a comparison of the superior province, Canada and the Dharwar craton, India. Geological Society, London, Special publications 121, 63-98.

Chuang, F.C., Noe Dobrea E. Z., Mest S. C. and Crown D. A., 2015. Geomorphologic mapping andmineralogy of pits in intercrater plains, northwest circum-Hellas region, Mars. Lunar and Planetary Science Conference, Abstract 2542.

Conway, S. J. and Balme, M. R., 2014. Decameter thick remnant glacial ice deposits on Mars. Geophysical Research Letters 41 (15), 5402-5409.

Crown, D.A., Bleamaster, L.F., and Mest, S.C., 2005. Styles and timing of volatile-driven activity in the eastern Hellas region of Mars. Journal of Geophysical Research 110, E12S22, doi:10.1029/2005JE002496.

Crown, D. A., Bleamaster, L. F., Mest, S. C., Mustard, J. F., and Vincendon, M., 2010. Geologic mapping of the NW rim of Hellas basin, Mars: Evidence for an Ancient Buried Landscape. Lunar and Planetary Science Conference, 1888.

De Blasio, F., 2014. Investigating the hydrology of the alleged Hellas Planitia lake in southern Mars. Lunar and Planetary Science Conference, Abstract 1511.

De Hon, R. A., 1992. Martian lake basins and lacustrine plains. Earth Moon and Planets 56, 95-122.

Diot, X., El-Maarry, M., Schlunegger, F., Norton, K., Thomas, N. and Grindrod, P., 2014. The geomorphology and morphometry of the banded terrain in Hellas basin, Mars. Planetary and Space Science 101 (0), 118-134.

Edwards, C. S., Nowicki, K. J., Christensen, P. R., Hill, J., Gorelick, N. and Murray, K., 2011. Mosaicking of global planetary image datasets: 1. Techniques and data processing for Thermal Emission Imaging System, (THEMIS) multi-spectral data. Journal of Geophysical Research: Planets 116 (E10).

Ehlmann, B. L., Mustard, J. F., Murchie, S. L., Bibring, J.-P., Meunier, A., Fraeman, A. A. and Langevin, Y., 2011. Subsurface water and clay mineral formation during the early history of Mars. Nature 479, 53-60. 
Ehlmann, B. L. and Edwards, C. S., 2014. Mineralogy of the martian surface. Annual Review of Earth and Planetary Sciences 42 (1), 291-315.

El-Maarry M.R., W. Watters, N. McKeown, J. Carter, E. Noe Dobrea, J. Bishop, A. Pommerol, N. Thomas, 2014. Putative Desiccation Cracks on Mars: A Synthesis from Modeling, Analogue-Field Studies, and Global Observations, Icarus 241, 248-268.

Encrenaz, T., Fouchet, T., Melchiorri, R., Drossart, P., Gondet, B., Langevin, Y., Bibring, J.P., Forget, F. and Bézard, B., 2006. Seasonal variations of the martian CO over Hellas as observed by OMEGA/Mars Express. Astronomy and Astrophysis 459, 265-270.

Fassett, C. I. and Head, III, J.W., 2008. The timing of martian valley network activity: constraints from buffered crater counting. Icarus 195 (1), 61-89.

Fergason, R. L., Christensen, P. R., Bell, J. F., Golombek, M. P., Herkenhoff, K. E. and Kieffer, H. H., 2006a. Physical properties of the Mars Exploration Rover landing sites as inferred from Mini-TES "derived thermal inertia". Journal of Geophysical Research: Planets 111 (E2).

Fergason, RL., Christensen, PR. and Kieffer, HH., 2006b. High-resolution thermal inertia derived from the Thermal Emission Imaging System (THEMIS): thermal model and applications. Journal of Geophysical Research 111 DOI: 10.1029/2006JE002735.

Forget, F., Haberle, R., Montmessin, F., Levrard, B. and Head, J., 2006. Formation of glaciers on Mars by atmospheric precipitation at high obliquity. Science 311, 368-371.

Forsythe, R. and Blackwelder, C., 1998. Closed drainage crater basins of the Martian highlands: constraints on the early martian hydrologic cycle, Journal of Geophysical Research 103, 31421-31432.

Fortezzo, C. M. and Skinner, J. A., 2013. Geologic history of Runanga-Jorn basin, northeast Hellas, Mars: based on modeled crater ages. Lunar and Planetary Science Conference, Abstract 2104.

Giani, G. P., 1992. Rock slope stability analysis. CRC Press.

Gorelick, N. S., Weiss-Malik, M., Steinberg, B. and Anwar, S., 2003. JMARS: A Multimission Data Fusion Application. S. Mackwell and E. Stansbery. Lunar and Planetary Science Conference, Abstract 2057.

Graf, J. E., Zurek, R. W., Eisen, H. J., Jai, B., Johnston, M. and DePaula, R., 2005. The Mars Reconnaissance Orbiter Mission. Acta Astronautica 57, 566-578.

Grassi, D., Formisano, V., Forget, F., Fiorenza, C., Ignatiev, N., Maturilli, A. and Zasova, L., 2007. The martian atmosphere in the region of Hellas basin as observed by the planetary Fourier spectrometer, (PFS-MEX). Planetary and Space Science 55 (10), 1346-1357.

Grohmann C. H. and Riccomini C., 2009. Comparison of roving-window and searchwindow techniques for characterizing landscape morphometry. Computers and Geosciences 35, 2164-2169.

Haberle, R. M., McKay, C. P., Schaeffer, J., Cabrol, N. A., Grin, E. A., Zent, A. P. and Quinn, R., 2001. On the possibility of liquid water on present-day Mars. Journal of Geophysical Research: Planets 106 (E10), 23317-23326.

Haberle, R. M., Murphy, J. R. and Schaeffer, J., 2003. Orbital change experiments with a Mars general circulation model. Icarus 161 (1), $66-89$.

Hall, K. and André, M.-F., 2001. New insights into rock weathering from high-frequency rock temperature data: an Antarctic study of weathering by thermal stress. Geomorphology 41 (1), 23-35.

Head, J., Neukum, G., Jaumann, R., Hiesinger, H., Hauber, E., Carr, M., Masson, P., Foing, B., Hoffmann, H., Kreslavsky, M., Werner, S., Milkovich, S., van Gasselt, S. and Team HRSC, 2005. Tropical to mid-latitude snow and ice accumulation, flow and glaciation on Mars. Nature 434, 346-351.

Head, J. W., Kreslavsky, M. A. and Marchant, D. R., 2011. Pitted rock surfaces on Mars: A 
mechanism of formation by transient melting of snow and ice. Journal of Geophysical Research: Planets 116 (E9).

Heldmann, J., Pollard, W., McKay, C., Marinova, M., Davila, A., Williams, K., Lacelle, D. and Andersen, D., 2013. The high elevation Dry Valleys in Antarctica as analog sites for subsurface ice on Mars. Planetary and Space Science 85 (0), 53-58.

Hon, K., Kauahikaua, J., Denlinger, R. and Mackay, K., 1994. Emplacement and inflation of pahoehoe sheet flows: observations and measurements of active lava flows on Kilauea Volcano, Hawaii. Geological Society of America Bulletin 106 (3), 351-370.

Howard, A.; Moore, J. and Irwin, R., 2005. An intense terminal epoch of widespread fluvial activity on early Mars: 1. Valley network incision and associated deposits. Journal of Geophysical Research (Planets) 110 (E9), 12.

Howard, A. D., Spiga, A. and Moore, J. M., 2012. The deepest basin on Mars is formed by an aeolian erosion. Lunar and Planetary Science Conference, Abstract 1105.

Hubbard, B., Milliken, R. E., Kargel, J. S., Limaye, A. and Souness, C., 2011. Geomorphological characterisation and interpretation of a mid-latitude glacier-like form: Hellas Planitia, Mars. Icarus 211 (1), 330-346.

Hubbard, B., Souness, C. and Brough, S., 2014. Glacier-like forms on Mars. The Cryosphere, 8, 2047-2061, doi:10.5194/tc-8-2047-2014.

Hudec, M. R. and Jackson M. P. A., 2007. Terra infirma: understanding salt tectonics. EarthScience Reviews 82, 1-28.

Kargel, J. S., Strom, R. G. and Johnson, N., 1991. Glacial geology of the Hellas Region on Mars. Lunar and Planetary Science Conference, Abstract 687.

Kirk, R. L., Howington-Kraus E., Redding B., Galuszka D., Hare T. M., Archinal B. A., Soderblom L. A. and Barrett J. M., 2003. High-resolution topomapping of candidate MER landing sites with Mars Orbiter Camera narrow-angle images. Journal of Geophysical Research, 108.

Kirk, R.L., Howington-Kraus, E., Rosiek, M.R., Anderson, J.A., Archinal, B.A., Becker, K. J., Cook, D.A., Galuszka, D.M., Geissler, P.E., Hare, T.M., Holmberg, I.M., Keszthe- lyi, L.P., Redding, B.L., Delamere, W.A., Gallagher, D., Chapel, J.D., Eliason, E.M., King, R., McEwen, A.S., 2008. Ultrahigh resolution topographic mapping of Mars with MRO HiRISE stereo images: meter-scale slopes of candidate Phoenix landing sites. Journal of Geophysical Research 113 (E3).

Kostama, V.P., Aittola, M., Raitala, J. and Цhman, T., 2001. The geology of the Hellas basin region: possible Mars Express HRSC target sites. AAS/Division for Planetary Sciences meeting, Abstracts 33.

Krause, M. O. and Grosfils, E. B., 2001. Analysis of Hellas rim geologic units using Mars Orbiter Laser Altimeter, (MOLA) Data. Lunar and Planetary Science Conference, Abstract 1108.

Leonard, G. J. and Tanaka, K. L., 1993. Hellas basin, Mars: formation by oblique impact. Lunar and Planetary Science Conference, pp. 867-868.

Leonard, G. J. and Tanaka, K. L., 2001. Geologic map of the Hellas region of Mars. U.S. Geological Survey Scientific Investigations Series Map I-2694, scale 1:5,000,000.

Leppänen, L. I., Kostama, V.-P. and Raitala, J., 2012. Oval structures on the floor of Hellas basin, Mars. Lunar and Planetary Science Conference, pp. 1784.

Lin, S., 2005. Synchronous vertical and horizontal tectonism in the Neoarchean: kinematic evidence from a synclinal keel in the northwestern Superior craton, Canada. Precambrian Research 139, 181-194.

Lowe, D., 1975. Water escape structures in coarse-grained sediments. Sedimentology 22, 157-204.

Madeleine, J.-B., J. W. Head, F. Forget, T. Navarro, E. Millour, A. Spiga, A. Colaïtis, A. 
Määttänen, F. Montmessin, and J. L. Dickson, 2014. Recent ice ages on Mars: The role of radiatively active clouds and cloud microphysics. Geophysical Research Letter, 41, 48734879, doi:10.1002/2014GL059861.

Malin, M. C. and Edgett, K. S., 2000. Sedimentary rocks of early Mars. Science 290 (5498), 1927-1937.

Malin, M.C., Bell, J.F., Cantor, B.A., Caplinger, M.A., Calvin, W.M., Clancy, R.T., Edgett, K.S., Edwards, L., Haberle, R.M., James, P.B., Lee, S.W., Ravine, M.A., Thomas, P.C., Wolff, M.J., 2007. Context Camera Investigation on board the Mars reconnaissance orbiter. Journal of Geophysical Research 112 (E5).

Mangold, N., 2003. Geomorphic analysis of lobate debris aprons on Mars at Mars Orbiter Camera scale: evidence for ice sublimation initiated by fractures. Journal of Geophysical Research: Planets 108, (E4).

Mangold, N. and Allemand, P., 2001. Topographic analysis of features related to ice on Mars, Geophysical Research Letters 28 (3), 407-410.

Mangold, N. and Allemand, P., 2003. Ductile deformation in Hellas floor: salt diapirs or crustal domes? Sixth International Conference on Mars, pp. 3047.

Martin, T. Z. and Richardson, M. I., 1993. New dust opacity mapping from Viking infrared thermal mapper data. Journal of Geophysical Research: Planets 98 (E6), 10941-10949.

Matsubara, Y., Howard, A. D. and Gochenour, J. P., 2013. Hydrology of early Mars: valley network incision. Journal of Geophysical Research: Planets 118 (6), 1365-1387.

Matsuoka, N., 1995. Rock weathering processes and landform development in the Sor Rondane mountains, Antarctica. Geomorphology 12 (4), 323-339.

Maxwell, T. A. and Craddock, R. A., 1995. Age relations of martian highland drainage basins. Journal of Geophysical Research: Planets 100 (E6), 11765-11780.

McEwen, A. S., Delamere, W. A., Eliason, E. M., Grant, J. A., Gulick, V. C., Hansen, C. J., Herkenhoff, K. E., Keszthelyi, L., Kirk, R. L., Mellon, M. T., Squyres, S. W., Thomas, N. and Weitz, C., 2002. HiRISE: The High Resolution Imaging Science Experiment for Mars Reconnaissance Orbiter. Lunar and Planetary Science Conference, pp. 1163.

McEwen, A. S., Eliason, E. M., Bergstrom, J. W., Bridges, N. T., Hansen, C. J., Delamere, W. A., Grant, J. A., Gulick, V. C., Herkenhoff, K. E., Keszthelyi, L., Kirk, R. L., Mellon, M. T., Squyres, S. W., Thomas, N. and Weitz, C. M., 2007. Mars Reconnaissance Orbiters High Resolution Imaging Science Experiment, HiRISE. Journal of Geophysical Research: Planets 112 (E5).

McEwen, A. S., Banks, M. E., Baugh, N., Becker, K., Boyd, A., Bergstrom, J. W., Beyer, R. A., Bortolini, E., Bridges, N. T., Byrne, S., Castalia, B., Chuang, F. C., Crumpler, L. S., Daubar, I., Davatzes, A. K., Deardorff, D. G., DeJong, A., Delamere, W. A., Dobrea, E. N., Dundas, C. M., Eliason, E. M., Espinoza, Y., Fennema, A., Fishbaugh, K. E., Forrester, T., Geissler, P. E., Grant, J. A., Griffes, J. L., Grotzinger, J. P., Gulick, V. C., Hansen, C. J., Herkenhoff, K. E., Heyd, R., Jaeger, W. L., Jones, D., Kanefsky, B., Keszthelyi, L., King, R., Kirk, R. L., Kolb, K. J., Lasco, J., Lefort, A., Leis, R., Lewis, K. W., Martinez-Alonso, S., Mattson, S., McArthur, G., Mellon, M. T., Metz, J. M., Milazzo, M. P., Milliken, R. E., Motazedian, T., Okubo, C. H., Ortiz, A., Philippoff, A. J., Plassmann, J., Polit, A., Russell, P. S., Schaller, C., Searls, M. L., Spriggs, T., Squyres, S. W., Tarr, S., Thomas, N., Thomson, B. J., Tornabene, L. L., Houten, C. V., Verba, C., Weitz, C. M. and Wray, J. J., 2010. The High Resolution Imaging Science Experiment, (HiRISE) during MRO Primary Science Phase, (PSP). Icarus 205 (1), 2-37.

Mellon, M. T., Jakosky, B. M., Kieffer, H. H. and Christensen, P. R., 2000. High-resolution thermal inertia mapping from the Mars Global Surveyor Thermal Emission Spectrometer. Icarus 148, 437-455.

Mège, D. and Ernst, R. E., 2001. Contractional effects of mantle plumes on Earth, Mars, and 
Venus. Geological Society of America Special paper 352, 103-140.

Mest, S. C., Crown, D.A. and Harbert, W., 2001. Highland drainage basins and valley networks in the eastern Hellas region of Mars. 32nd Lunar and Planetary Science, abstract $\# 1457$.

Mest, S. C. and Crown, D. A., 2005. Millochau crater, Mars: infilling and erosion of an ancient highland impact crater. Icarus 175 (2), $335-359$.

Mest, S.C., and Crown, D.A., 2006. Geologic Map of MTM -20272 and -25272 Quadrangles, Tyrrhena Terra region of Mars. U.S. Geological Survey Scientific Investigations Series Map 2934, scale 1:1,004,000.

Mest, S.C., Crown, D.A., and Harbert, W., 2010. Watershed modeling in the Tyrrhena Terra region of Mars. Journal of Geophysical Research 115, E09001, doi:10.1029/2009JE003429.

Milliken, R. E., Mustard, J. F. and Goldsby, D. L., 2003. Viscous flow features on the surface of Mars: observations from high-resolution Mars Orbiter Camera, (MOC) images. Journal of Geophysical Research: Planets 108 (E6).

Moore, J. M. and Edgett, K. S., 1993. Hellas Planitia, Mars: Site of net dust erosion and implications for the nature of basin floor deposits. Geophysical Research Letters 20 (15), $1599-1602$.

Moore, J. M. and Wilhelms, D. E., 2001. Hellas as a possible site of ancient ice-covered lakes on Mars. Icarus 154 (2), 258-276.

Moore, J. M. and Howard, A. D., 2005. Layered deposits and pitted terrain in the Circum Hellas region. 36th Annual Lunar and Planetary Science Conference, pp. 1512.

Moore, J. M. and Wilhelms, D. E., 2007. Geologic map of a part of western Hellas Planitia, Mars, U.S. Geological Survey Scientific Investigations Map 2953, scale 1:1,004,000.

Moura, P. A., Francelino, M. R., Schaefer, C. E. G., Simas, F. N. and de Mendon, B. A., 2012. Distribution and characterization of soils and landform relationships in Byers Peninsula, Livingston Island, Maritime Antarctica. Geomorphology 156 (0), 45-54.

Murchie, S., Arvidson, R., Bedini, P., Beisser, K., Bibring, J.-P., Bishop, J., Boldt, J., Cavender, P., Choo, T., Clancy, R. T., Darlington, E. H., Des Marais, D., Espiritu, R., Fort, D., Green, R., Guinness, E., Hayes, J., Hash, C., Heffernan, K., Hemmler, J., Heyler, G., Humm, D., Hutcheson, J., Izenberg, N., Lee, R., Lees, J., Lohr, D., Malaret, E., Martin, T., McGovern, J. A., McGuire, P., Morris, R., Mustard, J., Pelkey, S., Rhodes, E., Robinson, M., Roush, T., Schaefer, E., Seagrave, G., Seelos, F., Silverglate, P., Slavney, S., Smith, M., Shyong, W.-J., Strohbehn, K., Taylor, H., Thompson, P., Tossman, B., Wirzburger, M. and Wolff, M., 2007. Compact Reconnaissance Imaging Spectrometer for Mars, (CRISM) on Mars Reconnaissance Orbiter, MRO. Journal of Geophysical Research: Planets 112, E05S03, doi:10.1029/2006JE002682.

Nadin, P. A., Kusznir, N. J. And Toth, J., 1995. Transient regional uplift in the early Tertiary of the northern Notrh Sea and the development of Iceland plume. Geological Society Journal 152, 953-958.

Nelson, T. H., 1989. Style of salt diapirs as a function of the stage of evolution and the nature of the encasing sediments. In Gulf of Mexico salt tectonics, associated processes and exploration potential: Gulf Coast Section SEPM Foundation Tenth Annual Research Conference, pp. 109-110.

Ormö, J. and Komatsu, G., 2003. Mars Orbiter Camera observation of linear and curvilinear features in the Hellas basin: indications for multiple processes of formation. Journal of Geophysical Research: Planets 108, 5059, doi:10.1029/2002JE001980 (E6).

Osterloo, M. M., Hamilton, V. E., Bandfield, J. L., Glotch, T. D., Baldridge, A. M., Christensen, P. R., Tornabene, L. L. and Anderson, F. S., 2008. Chloride-bearing materials in the southern highlands of Mars. Science (319), 1651-1654. 
Osterloo, M. M., Anderson, F. S., Hamilton, V. E. and Hynek, B. M., 2010. Geologic context of proposed chloride-bearing materials on Mars. Journal of Geophysical Research: Planets 115, E10012, doi:10.1029/2010JE003613.

Pappalardo, R., Head, J. W., Greeley, R., Sullivan, R. J., Pilcher, C., Schubert, G., Moore, W. B., Carr, M. H., Moore, J. M., Belton, M. J. S. and Goldsby, D. L., 1998. Geological evidence for solid-state convection in Europa's ice shell. Nature 391, p. 365.

Pierce, T. L. and Crown, D. A., 2003. Morphologic and topographic analyses of debris aprons in the eastern Hellas region, Mars. Icarus (163), 46-65.

Piqueux, S. and Christensen, PR., 2009. A model of thermal conductivity for planetary soils: 1. Theory for unconsolidated soils. Journal of Geophysical Research 114 DOI: 10.1029/2008JE003308

Plaut, J. J., 2003. The Mars Odyssey Science Mission. AGU, Abstracts A1.

Putzig, N. E. and Mellon, M. T., 2007. Apparent thermal inertia and the surface heterogeneity of Mars. Icarus 191 (1), 68-94.

Rathbun, J. A., Musser Jr., G. S. and Squyres, S. W., 1998. Ice diapirs on Europa: implications for liquid water. Geophysical Research Letters 25, 4157-4160.

Read, P.L. and Lewis, S. R., 2004. The martian climate revisited: atmosphere and environment of a desert planet. Springer Science \& Business Media.

Ruff, SW., and Christensen P. R., 2002. Bright and dark regions on Mars: particle size and mineralogical characteristics based on Thermal Emission Spectrometer data. J. Geophys. Res. 107 DOI: 10.1029/2001JE001580.

Schenk, P. and Jackson, M. P. A., 1993. Diapirism on Triton, a record of crustal layering and instability. Geology 21, 299-302.

Schenk, P. M. and Zahnle, K., 2007. On the negligible surface age of Triton. Icarus 192 (1), 135-149.

Simpson, R. A., Tyler, G. L., Brenkle, J. P. and Sue, M., 1979. Viking bistatic radar observations of the Hellas basin on Mars-Preliminary results. Science (203), 45.

Smith, D. E., Zuber, M. T., Solomon, S. C., Phillips, R. J., Head, J. W., Garvin, J. B., Banerdt, W. B., Muhleman, D. O., Pettengill, G. H., Neumann, G. A., Lemoine, F. G., Abshire, J. B., Aharonson, O., David, C., Brown, Hauck, S. A., Ivanov, A. B., McGovern, P. J., Zwally, H. J. and Duxbury, T. C., 1999. The Global Topography of Mars and Implications for Surface Evolution. Science 284 (5419), 1495-1503.

Smith, D. E., Zuber, M. T., Frey, H. V., Garvin, J. B., Head, J. W., Muhleman, D. O., Pettengill, G. H., Phillips, R. J., Solomon, S. C., Zwally, H. J., Banerdt, W. B., Duxbury, T. C., Golombek, M. P., Lemoine, F. G., Neumann, G. A., Rowlands, D. D., Aharonson, O., Ford, P. G., Ivanov, A. B., Johnson, C. L., McGovern, P. J., Abshire, J. B., Afzal, R. S. and Sun, X., 2001. Mars Orbiter Laser Altimeter: Experiment summary after the first year of global mapping of Mars. Journal of Geophysical Research: Planets 106 (E10), 2368923722.

Souness, C., Hubbard, B., Milliken, R. E. and Quincey, D., 2012. An inventory and population-scale analysis of martian glacier-like forms. Icarus 217 (1), 243-255.

Squyres, S. W., 1979. The distribution of lobate debris aprons and similar flows on Mars. Journal of Geophysical Research: Solid Earth 84 (B14), 8087-8096.

Squyres, S. W. and Carr, M. H., 1986. Geomorphic Evidence for the Distribution of Ground Ice on Mars. Science 231(4735), 249-252.

Talbot, C. J. and Pohjola, V., 2009. Subaerial salt extrusions in Iran as analogues of ice sheets, streams and glaciers. Earth-Science Reviews 97, 155-183.

Tanaka, K. L. and Leonard, G. J., 1995. Geology and landscape evolution of the Hellas region of Mars. Journal of Geophysical Research: Planets 100 (E3), 5407-5432.

Tanaka, K.L., Robbins, S.J., Fortezzo, C.M., Skinner Jr, J.A. and Hare, T.M., 2014. The 
digital global geologic map of Mars: chronostratigraphic ages, topographic and crater morphologic characteristics, and updated resurfacing history. Planetary and Space Science 95, 11-24.

Tryka, K. A., Brown, R. H., Anicich, V. Cruikshank, D. P. and Owen, T. C., 1993. Spectroscopic determination of the phase composition and temperature of nitrogen ice on Triton. Science 261, 751-754.

Turcotte, D. L. and Schubert, G., 1982. Geodynamics: applications of continuum physics to geological problems, $450 \mathrm{pp}$.

Valbuzzi, E., Crosta, G.B. and De Blasio, F.V., 2014. Probable rock falls in the pits of Arsia Mons, Mars. Lunar and Planetary Science Conference, Abstract 2093.

Vendeville, B. Ci. And Jackson, P. A., 1992. The rise of diapirs during thin-skinned extension. Marine and Petroleum Geology 9, 331-354.

Werner, S., 2008. The early martian evolution: constraints from basin formation ages. Icarus 195 (1), 45-60.

Willmes, M., Reiss, D., Hiesinger, H. and Zanetti, M., 2012. Surface age of the ice-dust mantle deposit in Malea Planum, Mars, Planetary and Space Science 60 (1), 199 - 206.

Wilson, S.A., Howard, A.D., Moore, J.E., and Grant, J.A., 2007. Geomorphic and stratigraphic analysis of crater Terby and layered deposits north of Hellas basin, Mars. Journal of Geophysical Research 112, E08009.

Wilson, S. A., Moore, J. M., Howard, A. D. and Wilhelms, D. E.Cabrol, N. A. and Grin, E. A., 2010. Evidence for ancient lakes in the Hellas region. Lakes on Mars, Elsevier BV, 195-222.

Wilson, S. A., Grant, J. A. and Howard, A. D., 2012. Distribution of intracrater alluvial fans and deltaic deposits in the southern highlands of Mars. Lunar and Planetary Science Conference, Abstract 2462. 


\section{$\underline{\text { Tables and Figure captions }}$}

Table 1. Table of the values of thermal inertia used in this study to determine the composition (grain-size) of the different domains (image IDs, location and range of values with the standard deviation).

Table 2 (origin hypotheses). Table summarizing the various hypotheses of formation for the different domains of the NW of Hellas. This table provides the general morphology of each domains, the cross-cutting relationships between the domains and the possible formations mechanisms of the domains. The favored mechanism of formation is highlighted in the row “formations mechanism(s)".

Figure 1. (A) THEMIS day IR with MOLA colors map of the NW Hellas basin, which is our study area. The color outlines represent the different units for clarity. Colored outlines are: the Alpheus Colles plateau (red), the banded terrain (blue), the Honeycomb terrain (green), the reticulate terrain 1 (yellow), the reticulate terrain 2 (orange), the plain deposit 1 (black with dashed lines), and the plain deposit 2 (pink). The white boxes indicate the location of the other figures of this paper. The inset (B) represents a general THEMIS day IR map overlaid with MOLA color elevation map of the Hellas basin. The white box on this inset indicates the location of the Fig. 1A. (C) MOLA shaded relief map of the NW of the Hellas basin with white boxes that indicate the location of the other figures of the paper (example: " $8 A$ " shows the position of the figure $8 A$ of the paper).

Figure 2. CTX views of the different morphologies of banded terrain. (A) Linear bands (images IDs: P17_007768_1371, B18_16642_1371; image center: 42.6 $\left.{ }^{\circ} \mathrm{S}, 52.2^{\circ} \mathrm{E}\right)$; (B) Concentric bands (image IDs: P19_008559_1408, P17_007557_1386; image center: $39.4^{\circ}$ S, $\left.53.2^{\circ} \mathrm{E}\right) ;(C)$ Lobate bands, which are underlined by the white dashed lines (image ID: P17_007768_1371; image center: $\left.41.4^{\circ} \mathrm{S}, 51.7^{\circ} \mathrm{E}\right)$. 
Figure 3. Example of HiRISE images showing the texture of the surface of the bands. (A) HiRISE view (image ID: ESP_033560_1395; image center: $40.4^{\circ} \mathrm{S}, 51.8^{\circ} \mathrm{E}$ ) showing numerous clusters of boulders on the surface of a band; (B) HiRISE view (image ID: PSP_010563_1410; image center: $38.8^{\circ} \mathrm{S}, 55.5^{\circ} \mathrm{E}$ ) presenting an example of a halo of boulders around a fresh impact crater.

Figure 4. HiRISE view (image ID: PSP_006133_1410; image center: $38.7^{\circ} \mathrm{S}, 54.4^{\circ} \mathrm{E}$ ) showing a typical rockfall, which starts from the boundary of a lobate band. The blocks near the band are larger than the one at the end of the slope. Thus, the size of the falling blocks decreases away of the band.

Figure 5. HiRISE image (image ID: PSP_007623_1385; image center: $41.2^{\circ} \mathrm{S}, 51.2^{\circ} \mathrm{E}$ ) presenting the footprint of a viscous flow feature similar to the others observed on Mars as in the east of Hellas. (A) This HiRISE view presents the entire structure of the viscous flow. The nomenclature used is the one of Milliken et al. (2003): p.l for principal lobe, f.r: front ridges; (B) This HiRISE (same image) close up of the top of the structure reveals the presence of multiple boulders; (C) and (D) two HiRISE close-up of the termination of the viscous flow feature revealing the presence of the front ridges ( $f r)$ and terminal polygons respectively.

Figure 6. (A) HiRISE observation (image ID: PSP_006278_1410; image center: $38.8^{\circ} \mathrm{S}$, $55.5^{\circ} \mathrm{E}$ ) displaying possible dunes in the inter-bands; (B) HiRISE image (image ID: ESP_028589_1380; image center: $\left.41.6^{\circ} \mathrm{S}, 51.8^{\circ} \mathrm{E}\right)$ showing an example of the detachment of the band from a high-standing terrain, in this case the high-standing terrain is a part of the NW margin of the Alpheus Colles plateau.

Figure 7. CTX views presenting some honeycomb cells close to the banded terrain (A1 and A2) and others farther to the north of the banded terrain (B). On (A1) the cells display a banded material analogous to the linear bands (image ID: P17_007781_1414 and P15_006779_1414, B21_017710_1425; image A center: $\left.36.9^{\circ} \mathrm{S}, 55.6^{\circ} \mathrm{E}\right)$. The close-up 8A2) 
of the same CTX image shows the structures (pointed by white arrows) that can be interpreted as layers in the honeycomb cell; and on $(B)$ the honeycomb cells display a smooth to hummocky surface (images IDs B: P17_007860_1462 and P19_008361_1443; image B center: $\left.35.2^{\circ} \mathrm{S}, 58.6^{\circ} \mathrm{E}\right)$.

Figure 8. (A) CTX view (image IDs: B19_017011_1358, P19_008506_1359; image center: $\left.41.5^{\circ} \mathrm{S}, 59.5^{\circ} \mathrm{E}\right)$ of the layered knobs visible on the surface of the Alpheus Colles plateau. The layers are highlighted by white arrows. A sketch of the knobs indicated by the numbers 1, 2, 3 to illustrate the stack of layers is given on the right; (B) THEMIS daytime view of a lobate feature located on the top of the Alpheus Colles plateau (image center: $40.1^{\circ} \mathrm{S}, 68.3^{\circ} \mathrm{E}$ ).

Figure 9. CTX views (A1, A2 and B1) and sketch (B2) showing the cross-cutting relationships between the plain deposit 1 (P1) and the plain deposit 2 (P2). (A1) CTX image (image ID: B19_016919_1421, B19_017130_1422; image center: 39.37º, $51.6^{\circ}$ ) that shows P2 overlapping P1, the white arrows indicate the contact P1-P2; (A2) CTX close-up (image ID: B19_016919_1421) of the contact P1-P2 indicated by a white box on the Fig. 9A1, the white arrows show the morphological transition where P2 overlies P1; (B1) CTX observation (image ID: P19_008269_1420, B19_016919_1421, B19_017130_1422; image center: $\left.38.5^{\circ} \mathrm{S}, 51.5^{\circ} \mathrm{E}\right)$ that displays another example of the cross-cutting relationships between P1 and P2. On this image, the white arrows underline the contact P1-P2

Figure 10. (A1) CTX view (image ID: P17_007834_1426 and P19_008625_1425; image center: $37.5^{\circ} \mathrm{S}, 48.7^{\circ} \mathrm{E}$ ) showing the contact between the RTl and P1. In this figure, the P1 covers the RTI. The white box represent the location of the sketch (A2) located on the left of the CTX observation (A1). On (A2), the contact RT1-P1 is showed by the thicker white line. The white dashed lines on (A2) indicates the ridges of RT1 apparently covered by $P 1 ;(B)$ HiRISE view and a close-up $(C)$ of the same image (image ID: PSP_008058_1415, image center: $\left.38.1^{\circ} \mathrm{S}, 52.9^{\circ} \mathrm{E}\right)$ showing a possible fault network observed in RT2. 
Figure 11. HiRISE views (image ID: PSP_008058_1415; image center: $38.1^{\circ} \mathrm{S}, 52.9^{\circ} \mathrm{E}$ ) showing the contact between the RT2 and P2. (A) This HiRISE observation of the same image shows a degradation of $P 2$ forming the RT2. The surface of RT2 displays boulders as relic of the texture of P2; (B) HiRISE view of the same image revealing the imbrication of the ridges of $R T 2$ within the $P 2$. We can observe that the ridges of $R T 2$ propagate into the $P 2$ and $(C)$ close up showing the imbrication of $R T 2$ ridges within the $P 2$.

Figure 12. (A) HiRISE DTM's hillshade where the grayscale shows the illumination and (B) slope map of the same DTM where the red color indicates the higher slopes and the blue color shows gentler slope to flat terrains. The ridges and the floor of the depressions reveal a bluish color indicative of a flat surface, whereas near to the ridges the color is red indicative of high slopes. DTM built from the HiRISE image pair: ESP_024936_1435 and ESP_033494_1435.

Figure 13. Relief map on the left associated with profiles perpendicular to the ridges of RT2 on the right $\left(A-A^{\prime}, B-B^{\prime}\right)$. On these two profiles, we can note the relief of the depressions in the range 15-20 m. DTM built from the HiRISE image pair: ESP_024936_1435 and ESP_033494_1435.

Figure 14. CTX views showing the complex cross-cutting relationships between: the honeycomb terrain (noted HC), the plain deposit $2(P 2)$ and the reticulate terrain 2 (RT2). (A) On this CTX image (image ID: P14_006700_1386; image center: $38.8^{\circ} \mathrm{S}, 52.6^{\circ} \mathrm{E}$ ) the bulging material that forms the ridges of the HC cells seems to be made up of P2 material indicative of a reworking, a modification of P2 by the formation of the honeycomb terrain. (B1) This CTX observation illustrates the deformation of the ridges of RT2 by the honeycomb cells (image ID: P18_008058_1438; image center: $38.3^{\circ} \mathrm{S}, 53.02^{\circ} \mathrm{E}$ ). We can observe that some of the ridges of RT2 are twisted in contact with the honeycomb cells (HC). In addition some depressions of RT2 have a pinched-shape between two honeycomb cells as it is showed 
on the sketch B2. On the sketch B2 in the bottom right corner, the cells of the honeycomb are represented by the dashed areas and the ridges of $R T 2$ by the white lines.

Figure 15. Schema of the relative correlation of the different geomorphologic domains mapped and characterized in this study of the interior of the NW Hellas basin. This reconstruction is based on the cross-cutting relationships and geometric interactions between the different domains.

Figure 16. (A) Google Earth view showing an example of salt diapirs observable in Iran (Great Kavir salt diapirs); (B) Typical observation of the surface of the Neptune's moon Triton illustrating the Cantaloupe terrain (image credit: JPL/NASA/Voyager 2). These oval shapes have been interpreted has ice-diapirs formed due to the extrusion of an overpressured ice below the surface. 
Figures

Figure 1

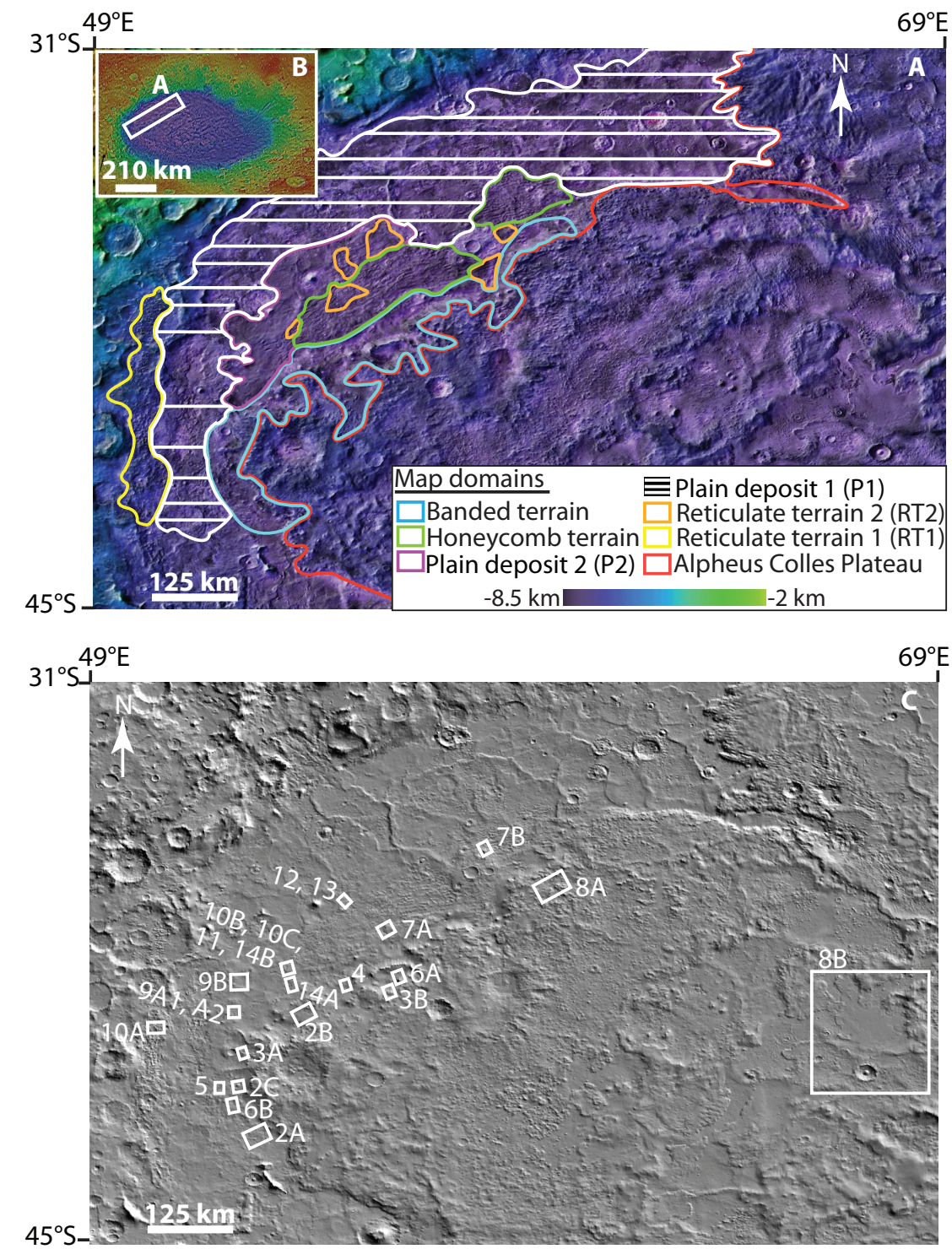


Figure 1 cont
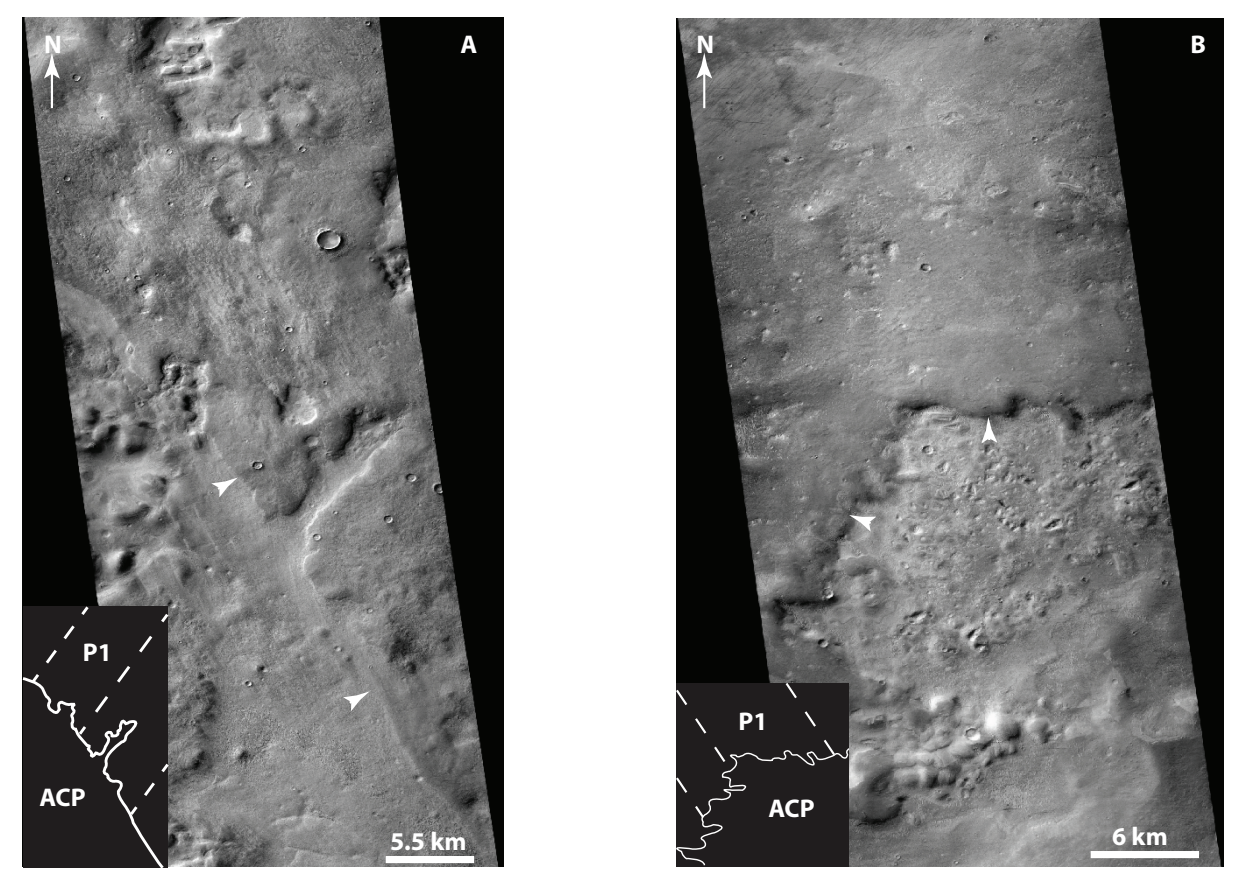
Figure 2
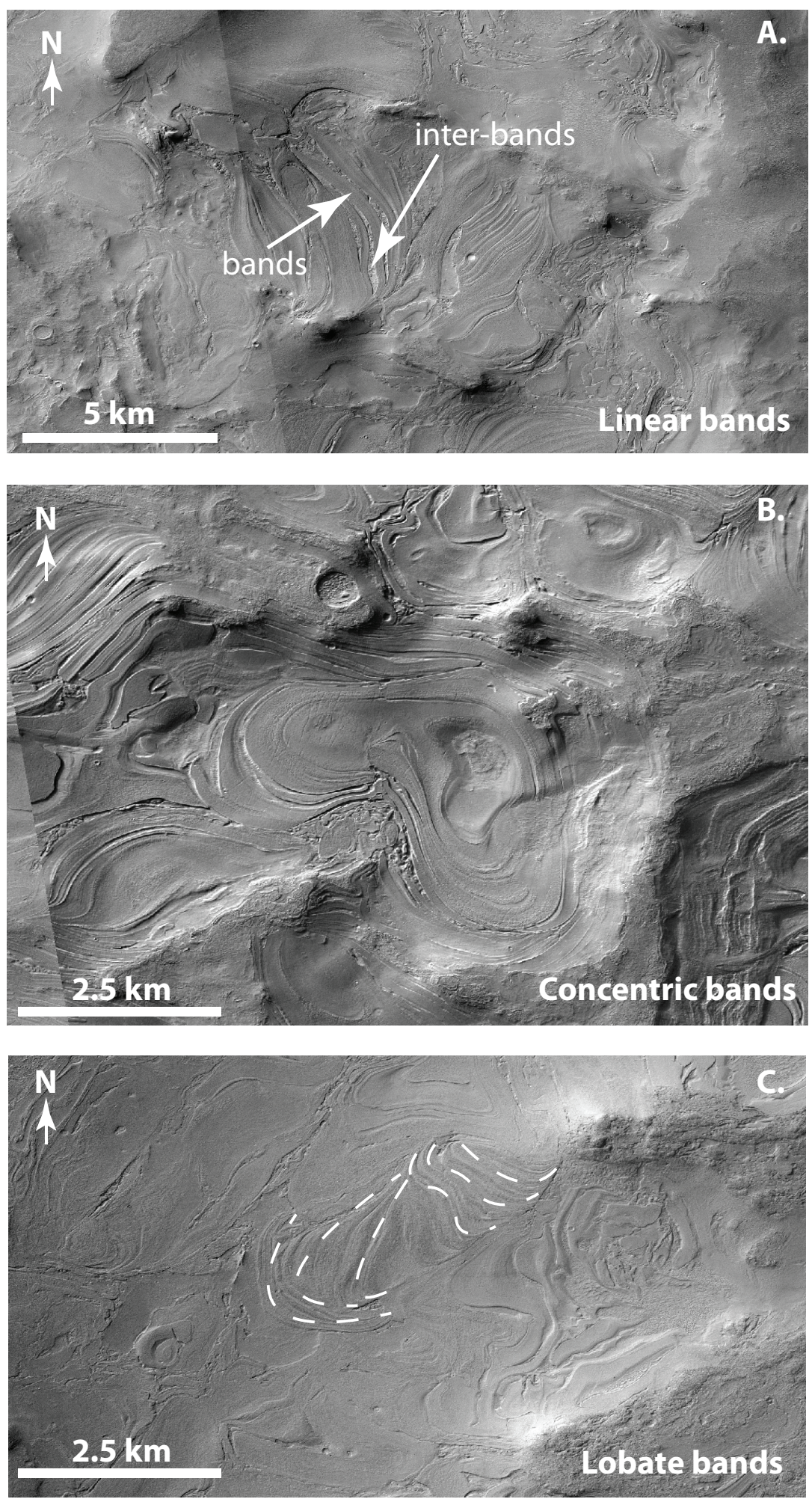

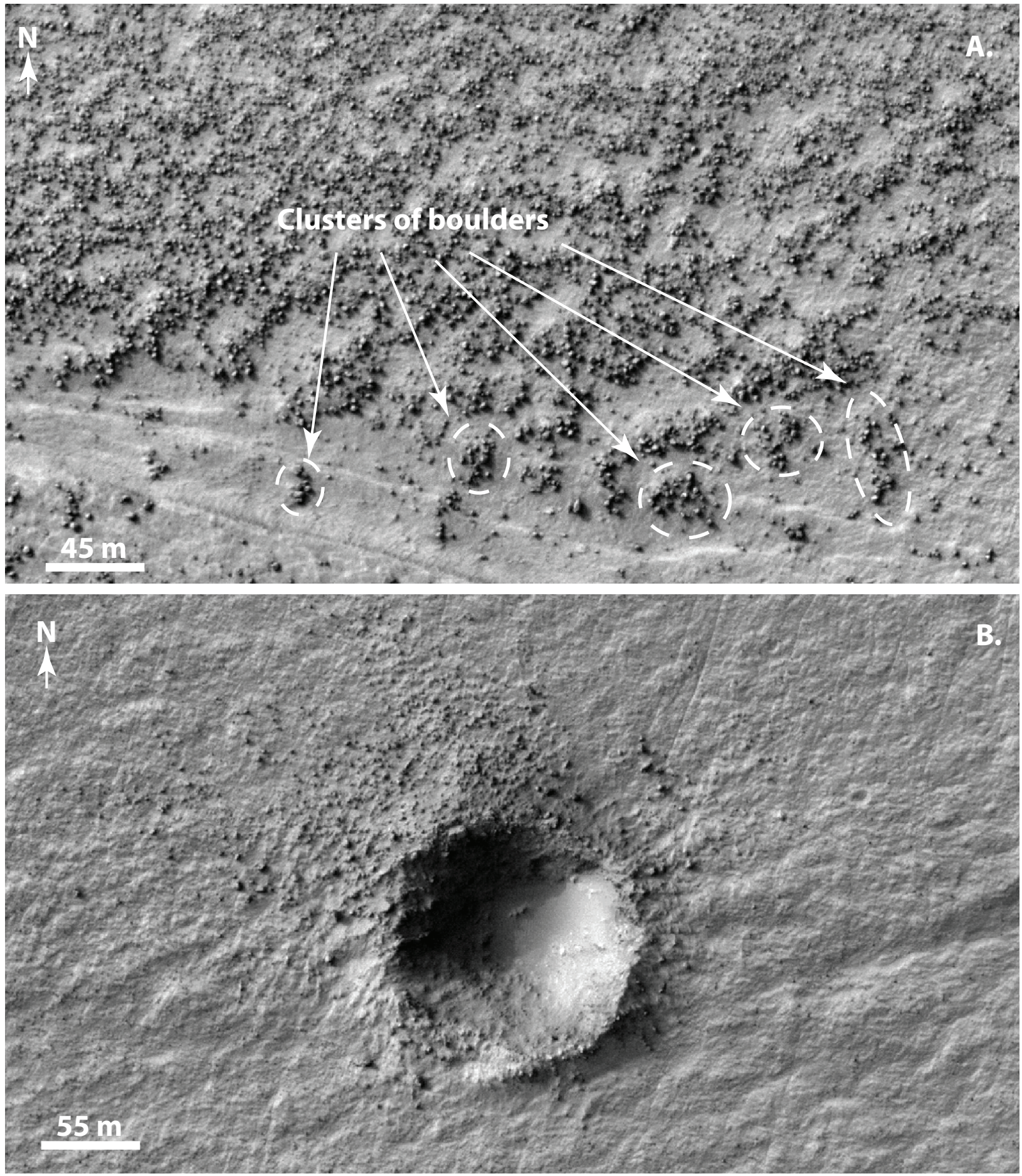
Figure 4

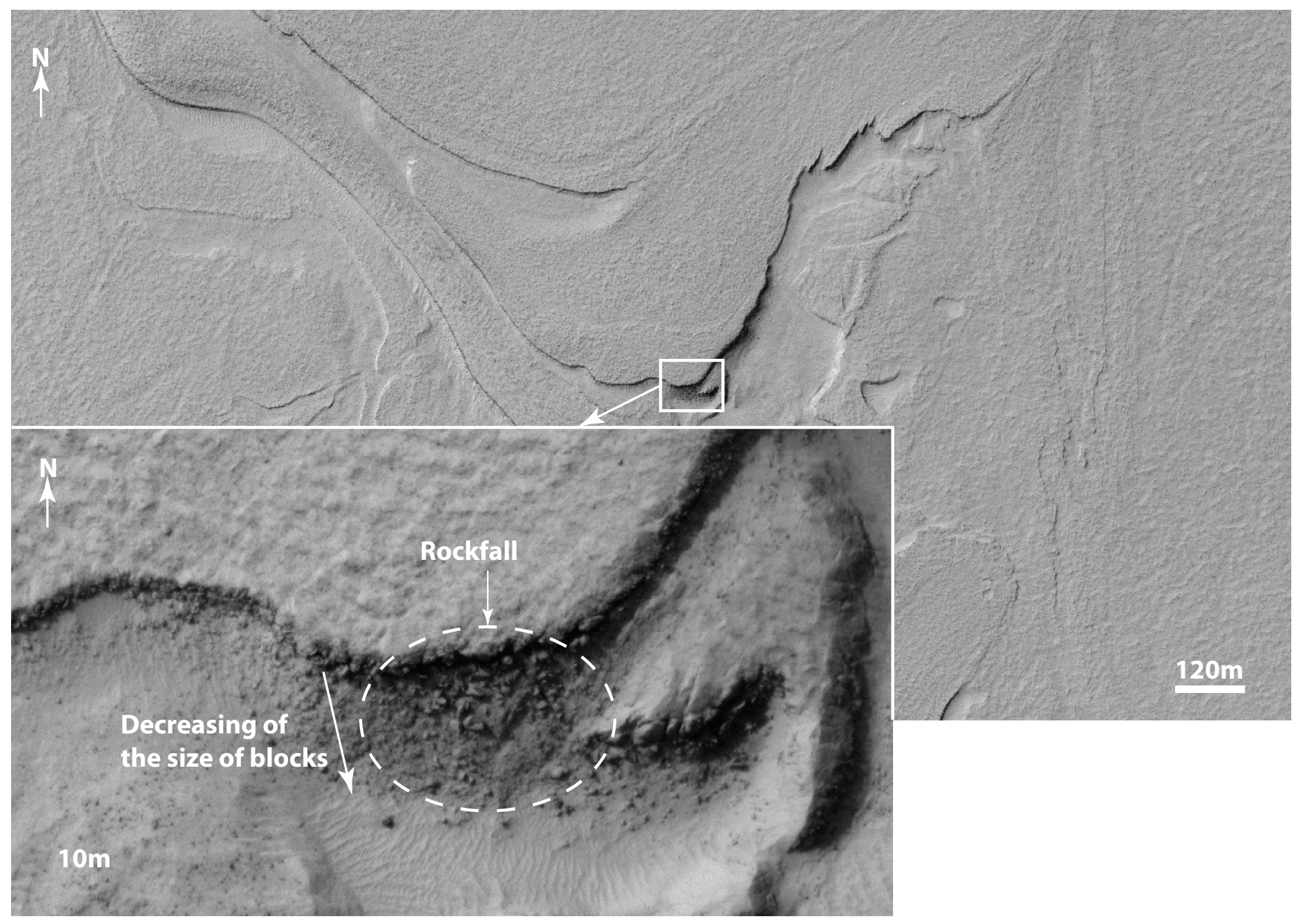




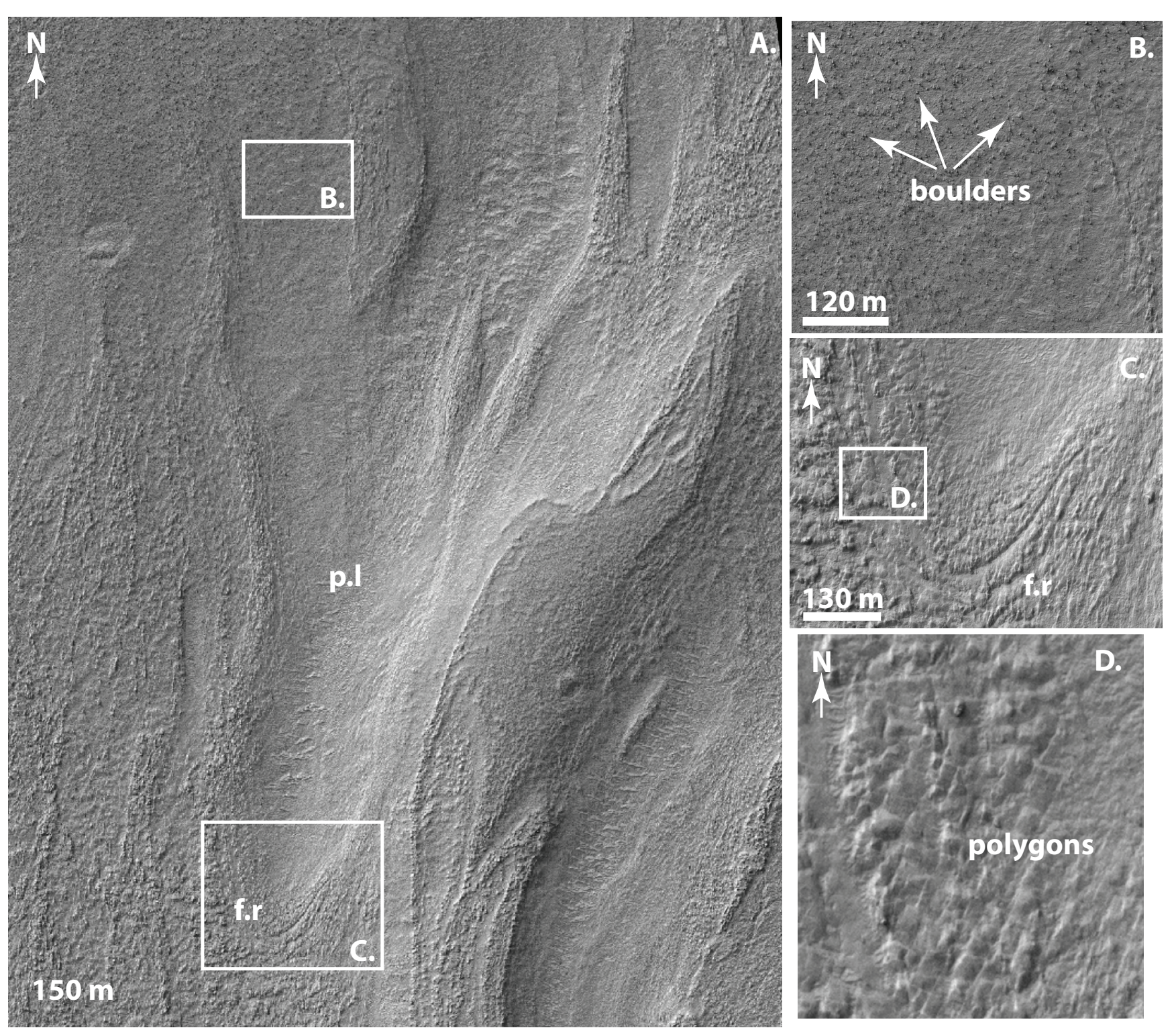


Figure 6
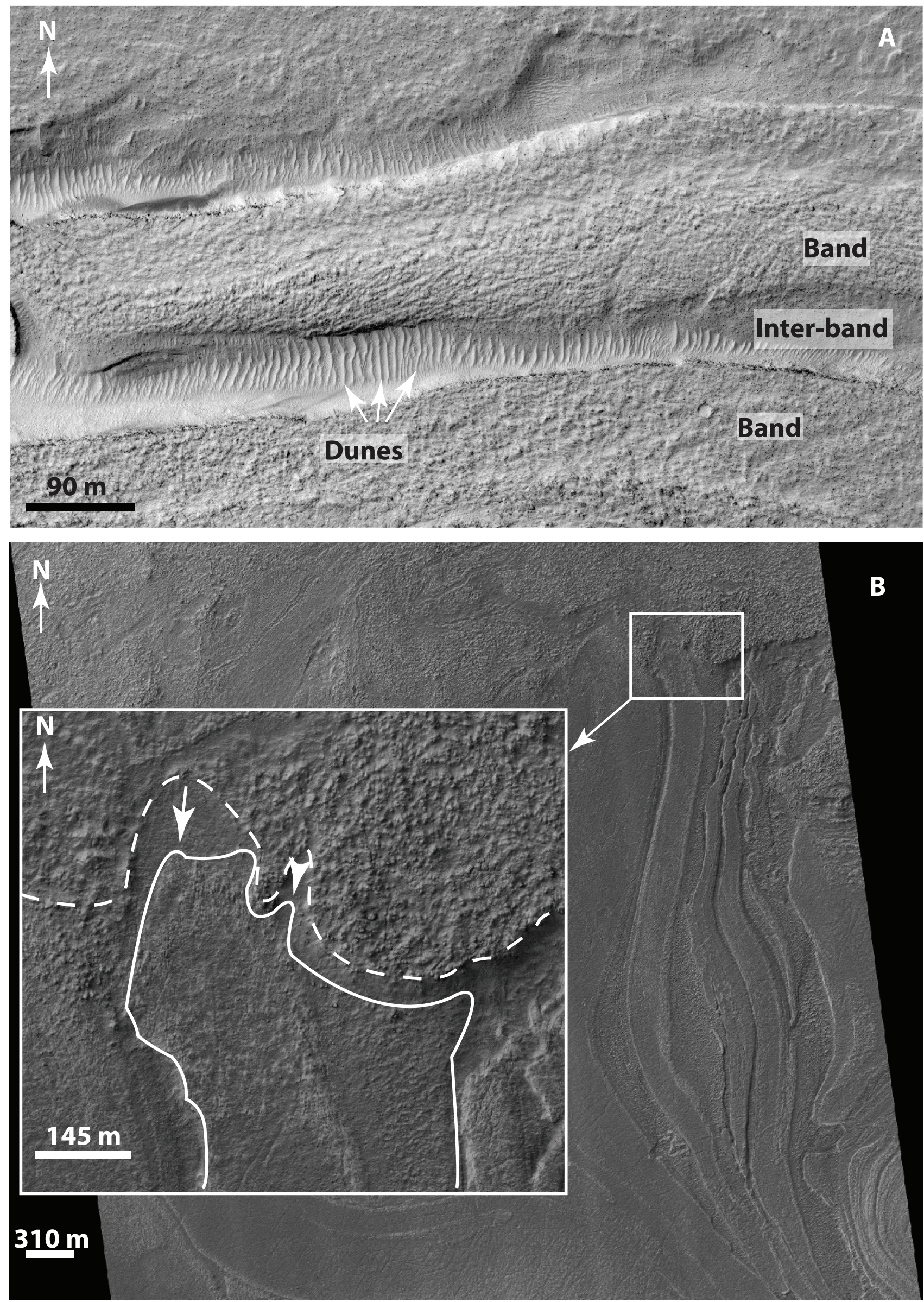
Figure 7
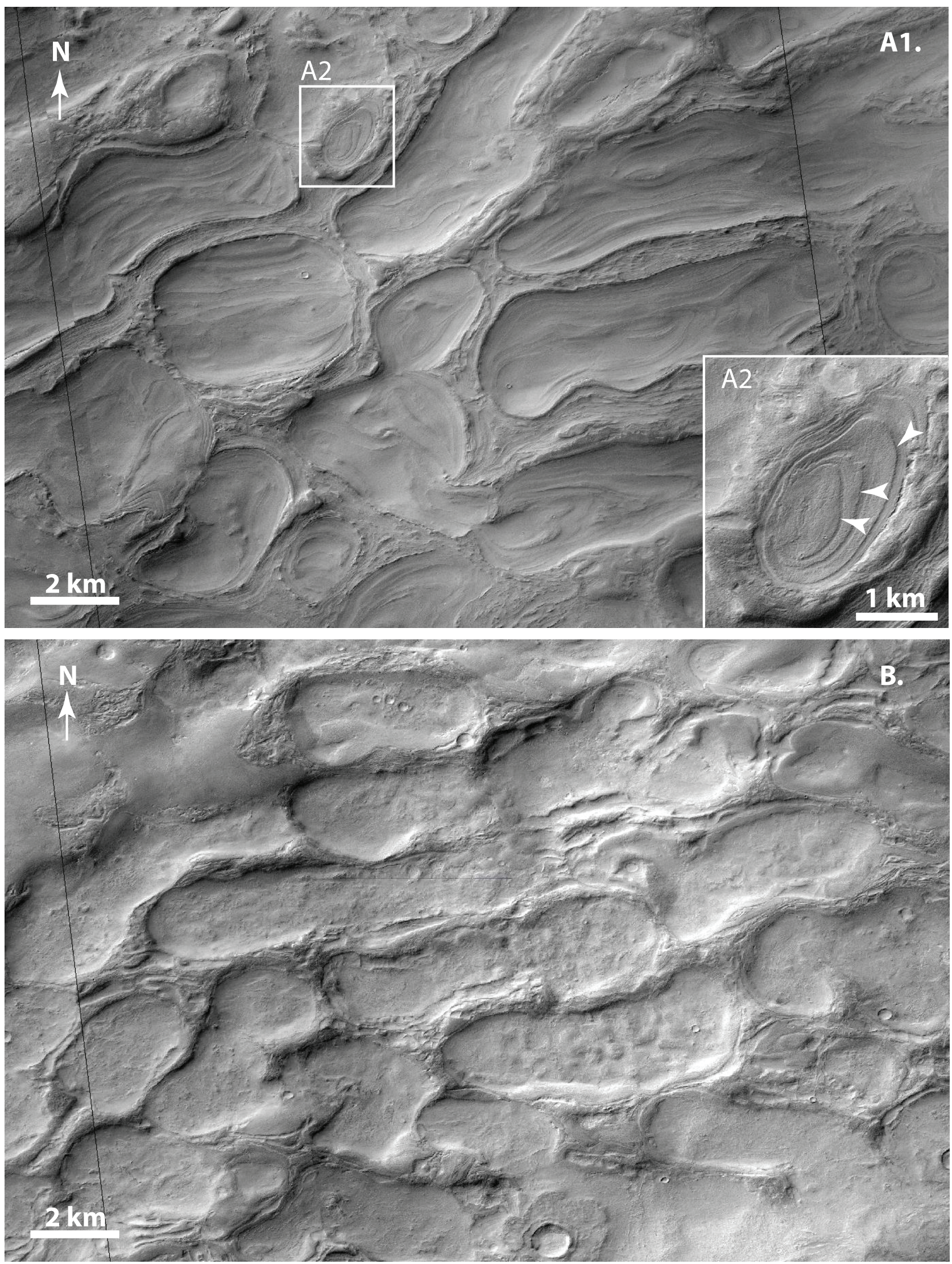

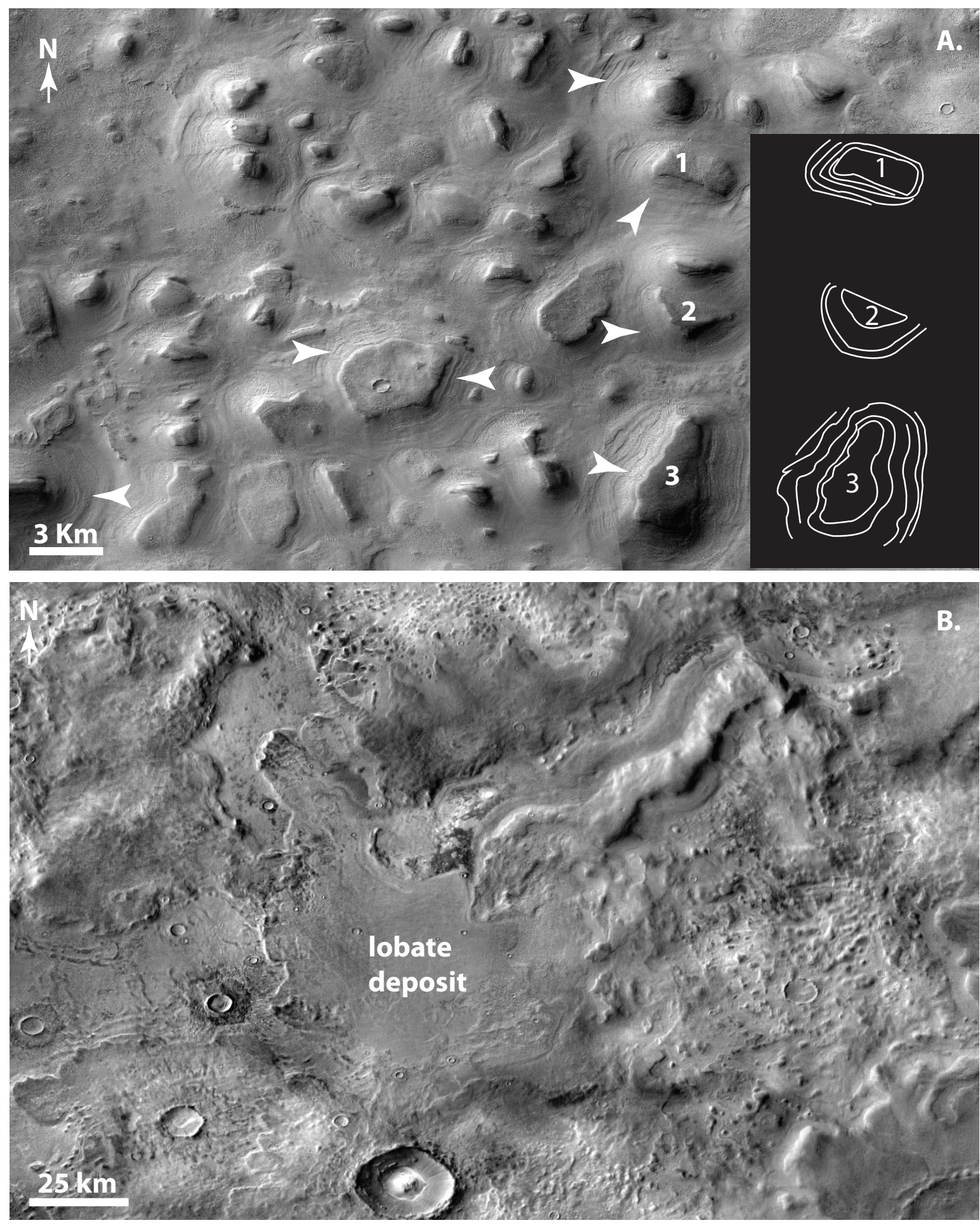
Figure 9
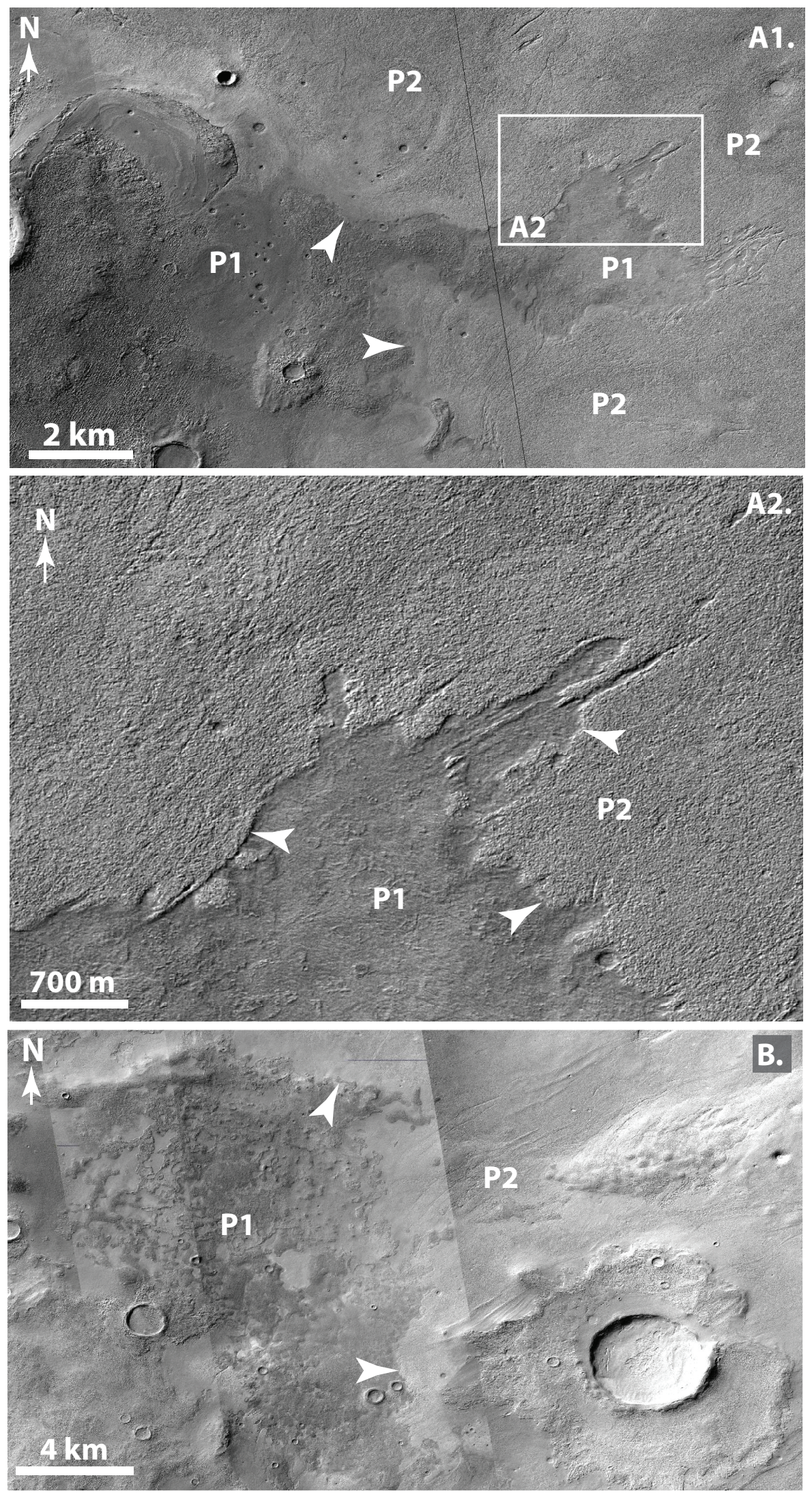
Figure 10
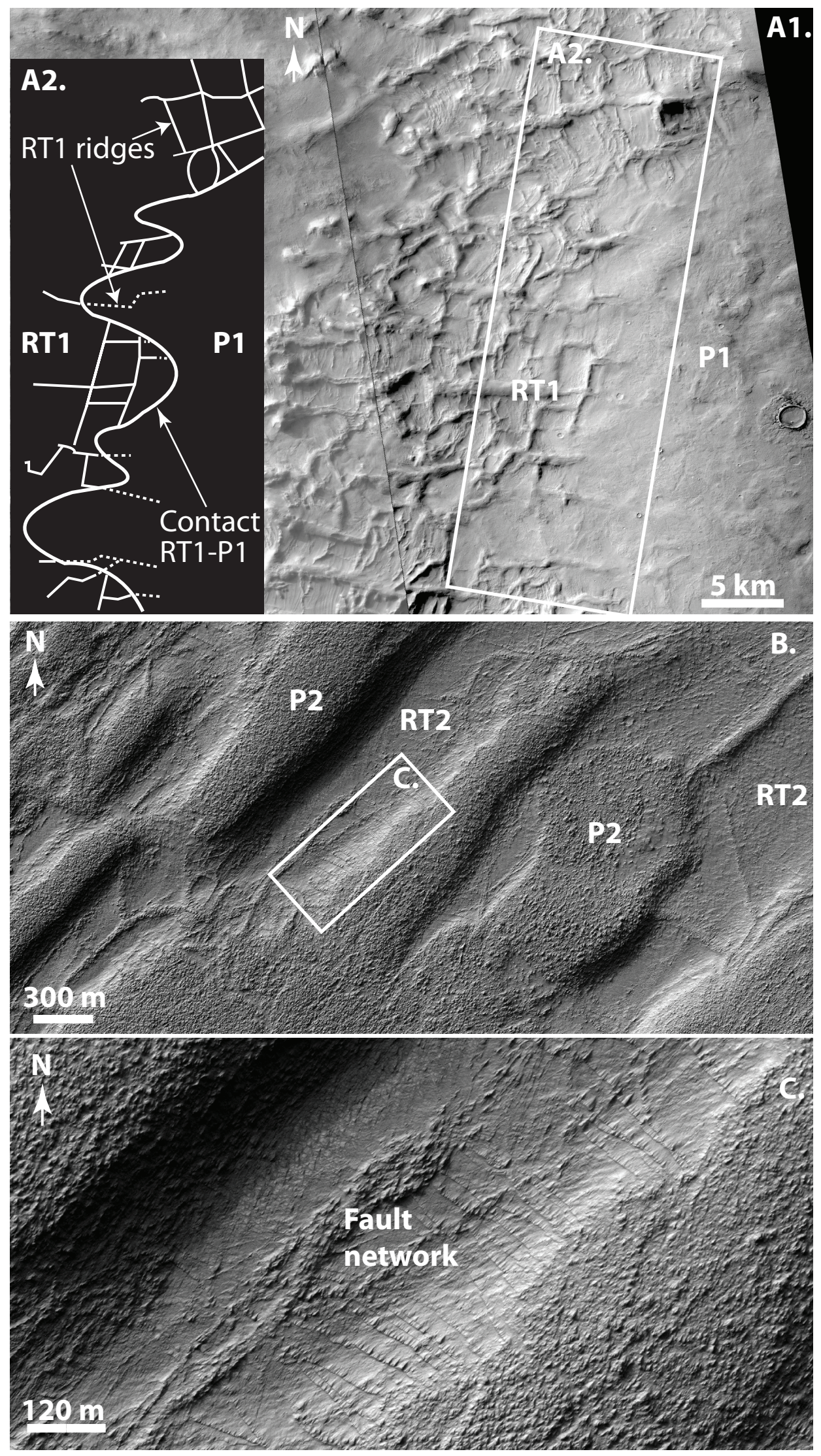
Figure 11
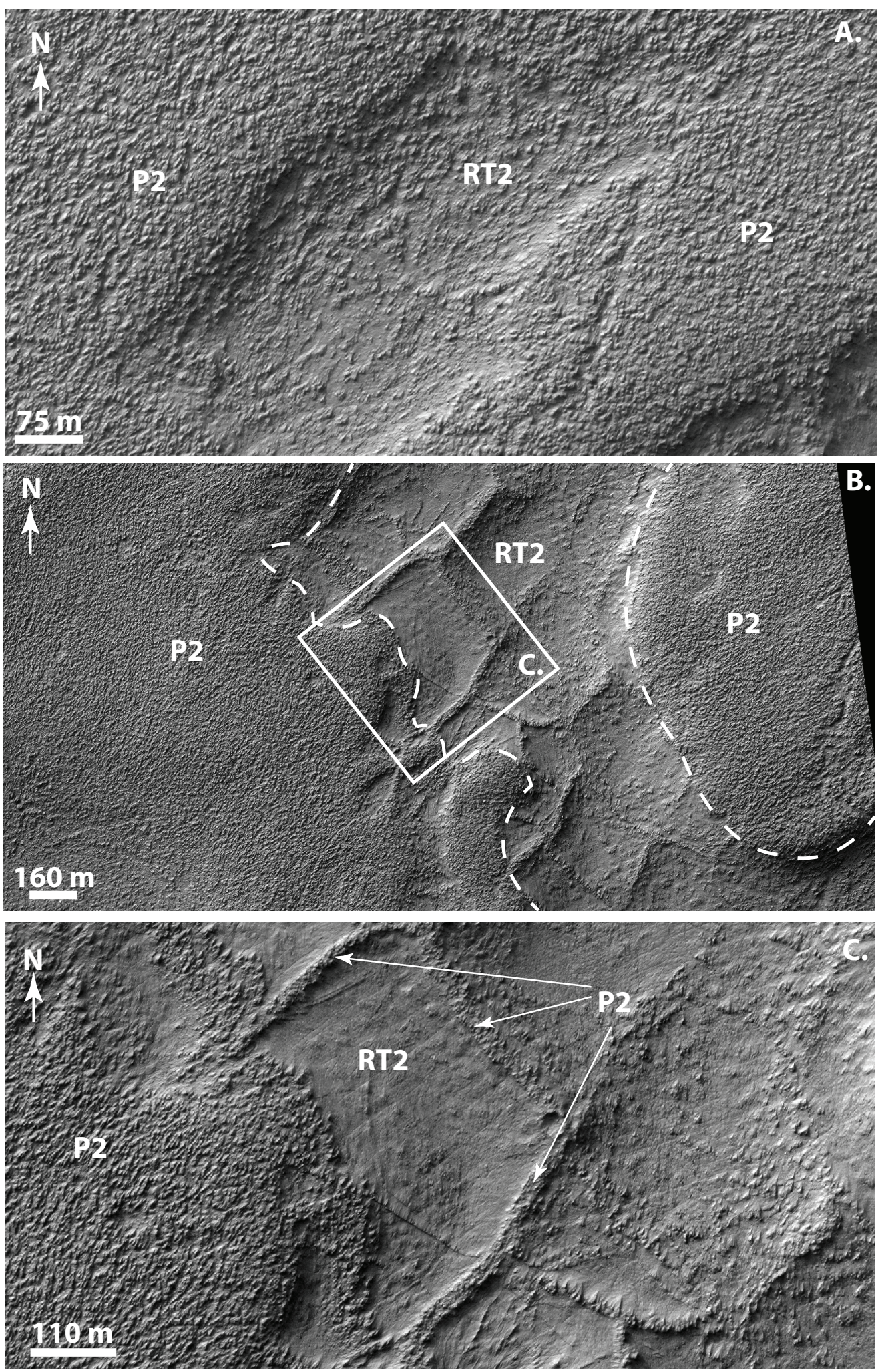


\section{Figure 12}

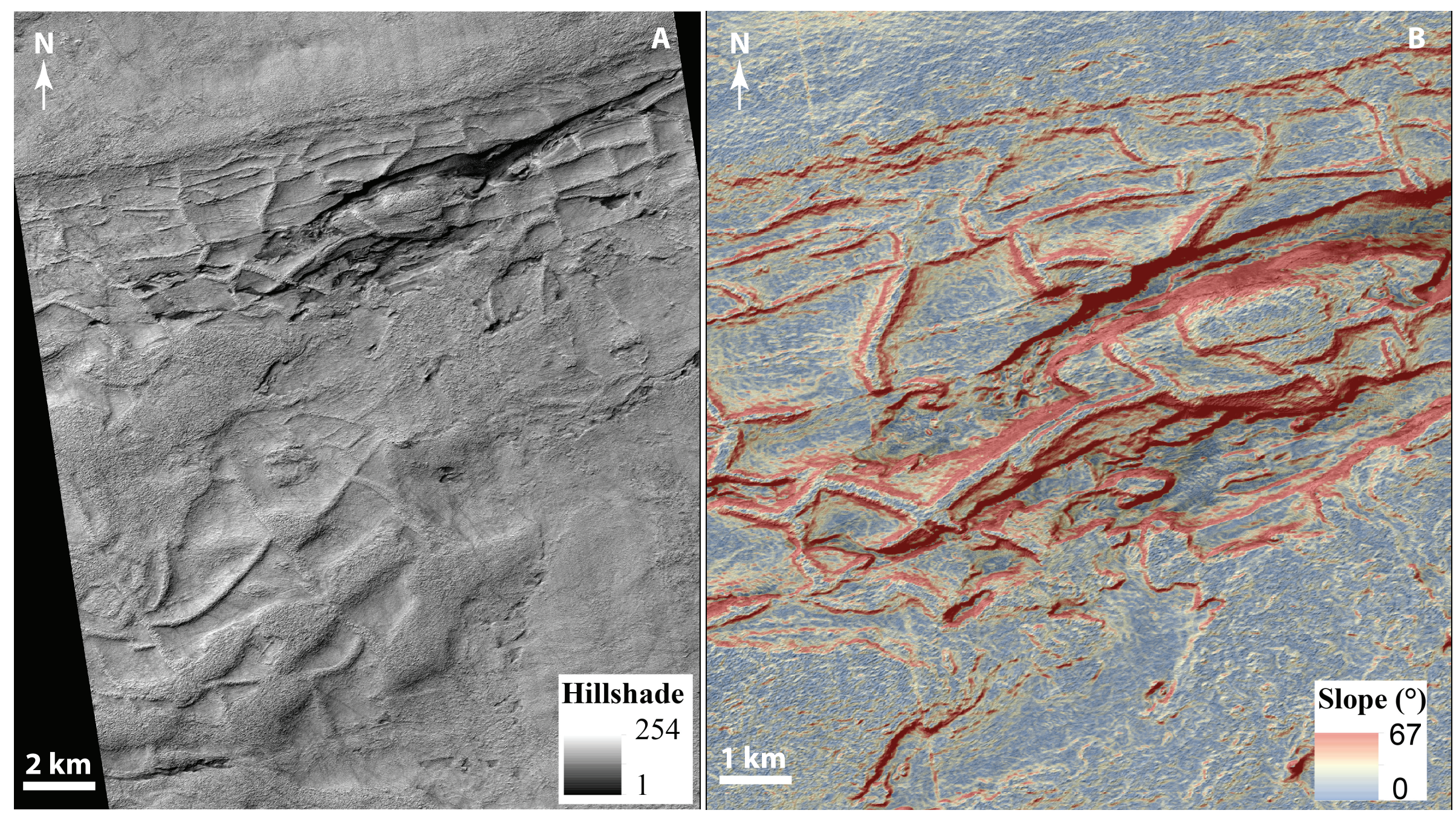


Figure 13
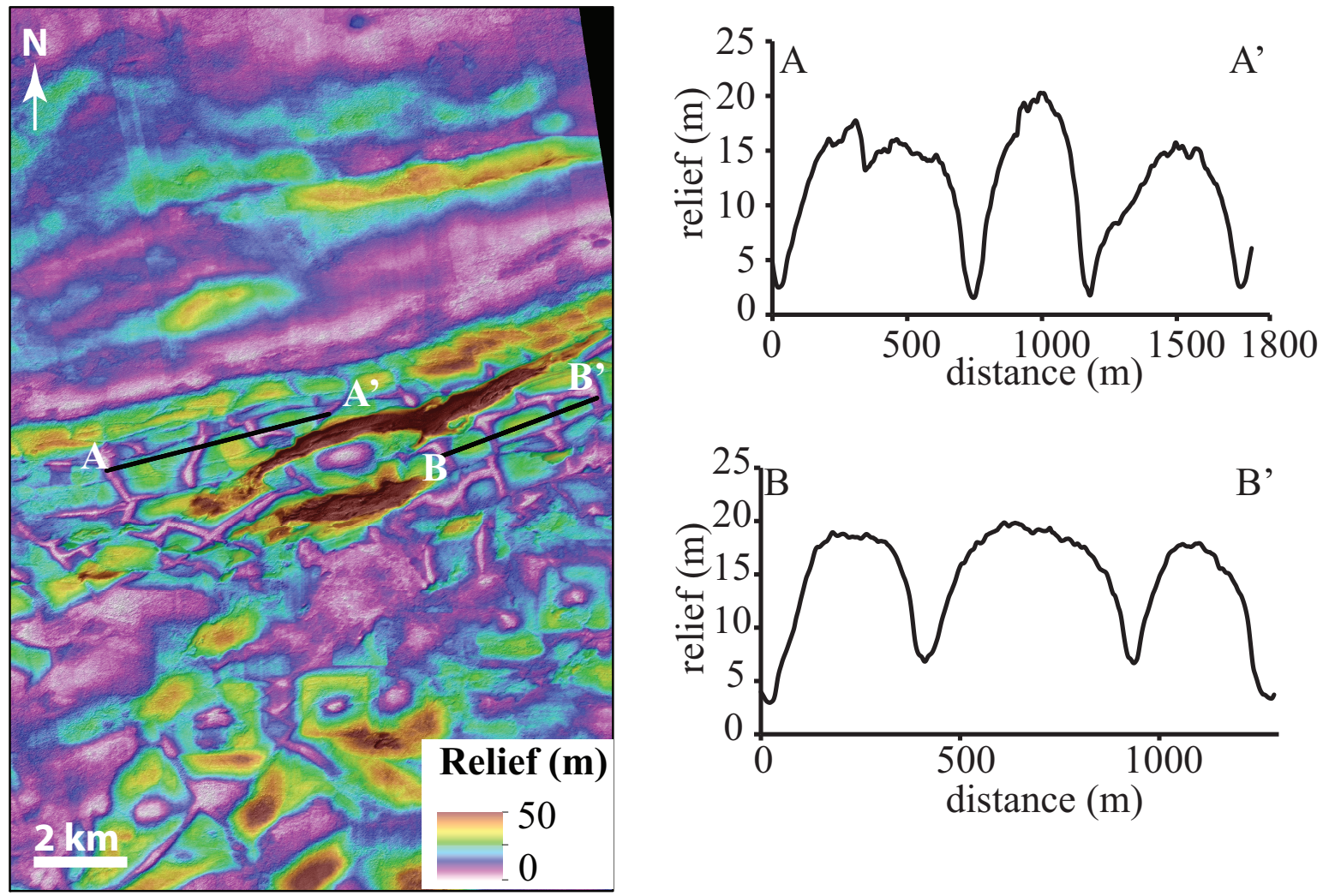
Figure 14
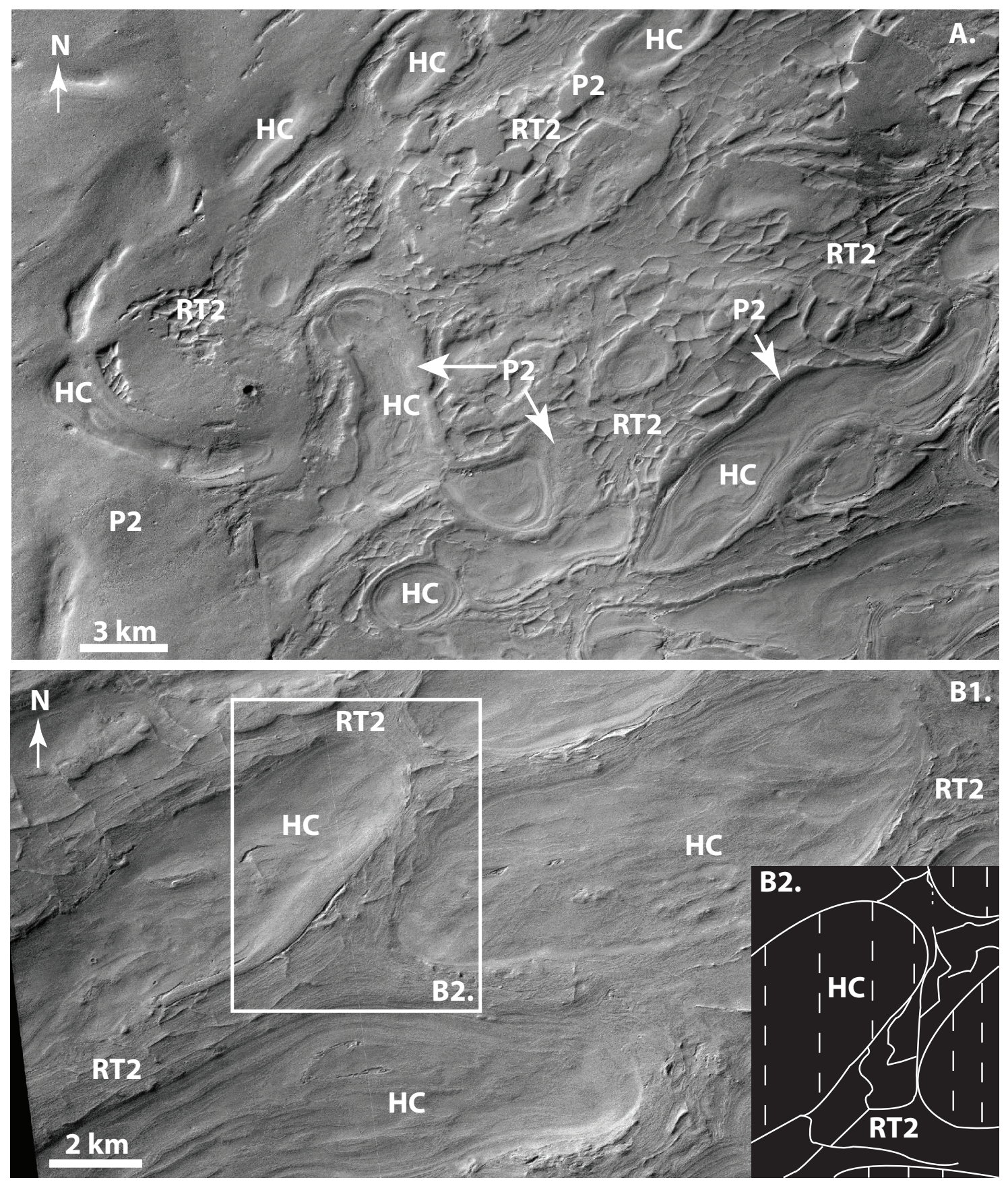


\section{Figure 15}

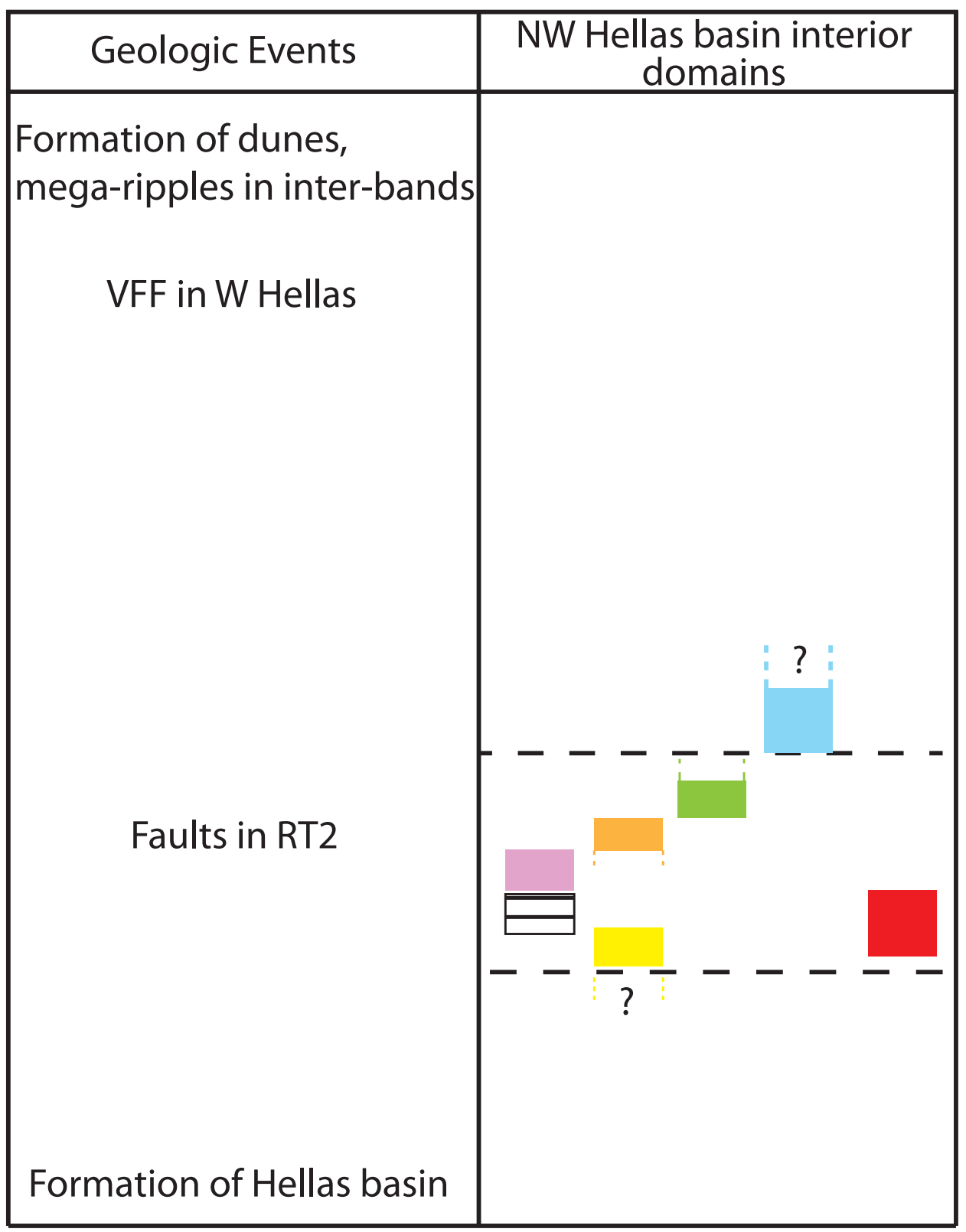

\section{Domains}

Banded terrain

Honeycomb terrain

Plain deposits 2 (P2)

Plain deposits 1 (P1)
Reticulate terrain 2 (RT2) Reticulate terrain 1 (RT1) Alpheus Colles plateau 
Figure 16
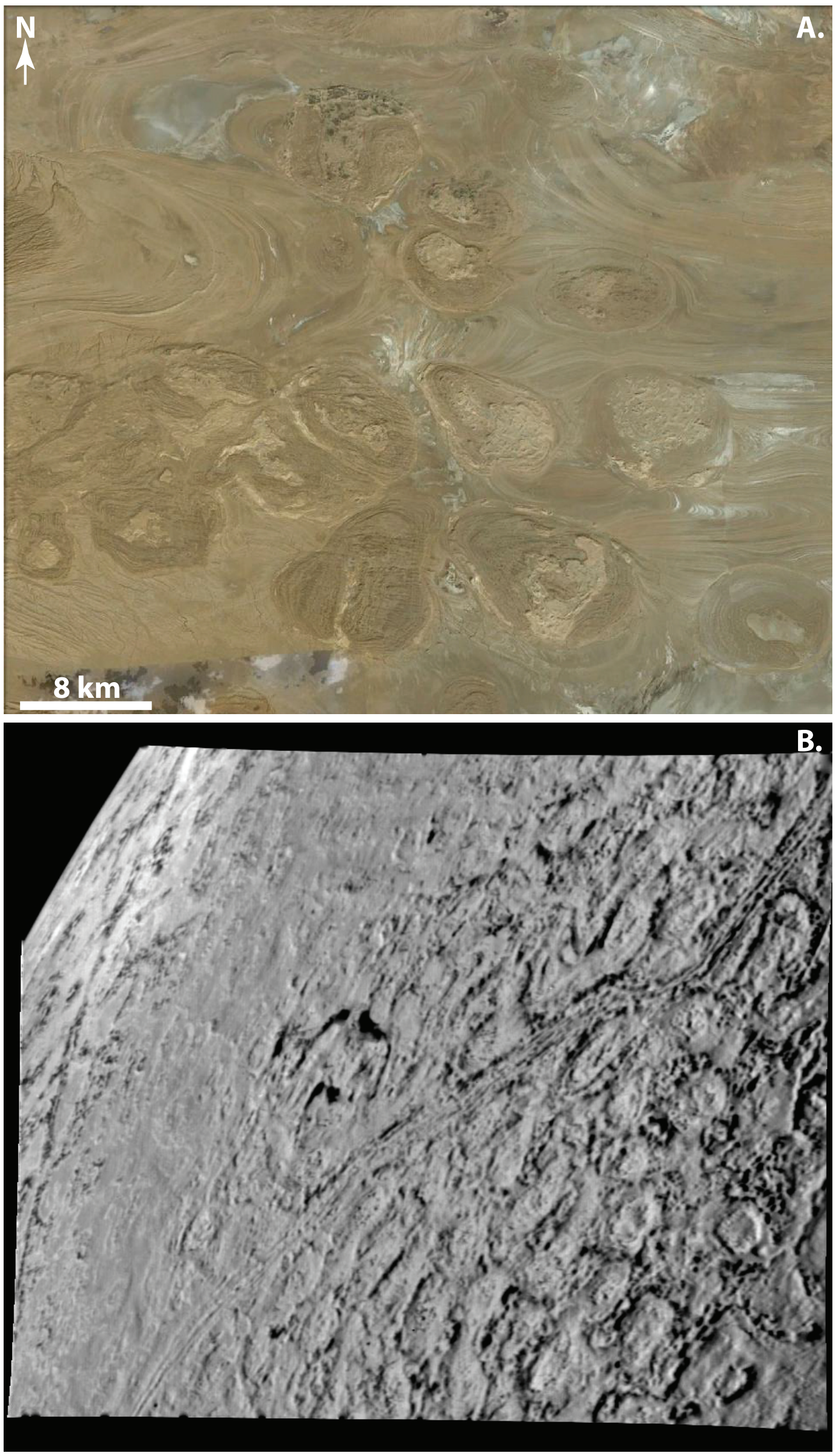


\begin{tabular}{|c|c|c|}
\hline Image ID & Unit & Location (latitude; longitude) \\
\hline $\mathrm{I} 08868006$ & plain deposits & $39^{\circ} \mathrm{S} ; 50.7^{\circ} \mathrm{E}$ \\
\hline $\mathrm{I} 34287002$ & honeycomb terrain & $36.9^{\circ} \mathrm{S} ; 55.2^{\circ} \mathrm{E}$ \\
\hline $\mathrm{I} 33713003$ & honeycomb terrain & $37.5^{\circ} \mathrm{S} ; 53.6^{\circ} \mathrm{E}$ \\
\hline $\mathrm{I} 34312007$ & honeycomb terrain & $37.5^{\circ} \mathrm{S} ; 54^{\circ} \mathrm{E}$ \\
\hline $\mathrm{I} 17978008$ & banded terrain & $39.2^{\circ} \mathrm{S} ; 54.8^{\circ} \mathrm{E}$ \\
\hline $\mathrm{I} 08531012$ & banded terrain & $42^{\circ} \mathrm{S} ; 52.2^{\circ} \mathrm{E}$ \\
\hline $\mathrm{I} 17953008$ & Alpheus Colles plateau & $38.9^{\circ} \mathrm{S} ; 56.2^{\circ} \mathrm{E}$ \\
\hline
\end{tabular}




\begin{tabular}{|c|}
\hline Thermal Inertia (tiu) \\
\hline P1: $230( \pm 30)-280( \pm 20)$ \\
\hline cells interior:250 $( \pm 38)-$ cells ridges: $400( \pm 60)$ \\
\hline cells interior: $250( \pm 38)$ - cells ridges: $400( \pm 60)$ \\
\hline cells interior: $250( \pm 38)-$ cells ridges: $400( \pm 60)$ \\
\hline inter-bands: $300( \pm 45)$ - bands: $450( \pm 68)$ \\
\hline inter-bands: $300( \pm 45)-$ bands: $450( \pm 68)$ \\
\hline$\sim 220( \pm 33)$ \\
\hline
\end{tabular}




\begin{tabular}{|c|c|c|c|}
\hline Domains & General morphology & Relative dating & Formations mechanism(s) \\
\hline $\begin{array}{l}\text { Alpheus Colles plateau (ACP) in } \\
\text { the center Hellas. }\end{array}$ & $\begin{aligned}> & \text { Large thick plateau. } \\
& \text { Belt of layered knobs in the } \\
& \text { NW part. Relatively smooth } \\
& \text { central part. } \\
> & \text { Sinuous NW margin } \\
> & \text { Fine-grained surface material } \\
& \text { (silt or fine sand). }\end{aligned}$ & $\begin{array}{l}>\quad \text { Overlapped in its eastern part } \\
\text { by } \mathrm{P} 2 \rightarrow \text { older than } \mathrm{P} 2 \\
\text { Overlaid by some banded } \\
\text { terrain } \rightarrow \text { older than banded } \\
\text { terrain }\end{array}$ & $\begin{array}{l}\text { Smooth central part could be } \\
\text { due to a remobilization of } \\
\text { an ice-rich mantle deposited } \\
\text { during high-obliquity phases. } \\
>\text { NW Knobs belt could be due } \\
\text { to the loss of ground ice }\end{array}$ \\
\hline $\begin{array}{l}\text { Banded terrain in the deepest part } \\
\text { of Hellas. }\end{array}$ & $\begin{array}{l}>\quad \begin{array}{l}\text { Alternation of sinuous bands } \\
\text { and inter-bands }\end{array} \\
>\quad \begin{array}{l}\text { Periglacial features on the } \\
\text { surface. }\end{array} \\
>\quad \text { Fine-coarse partially } \\
\text { cemented sand or silt. }\end{array}$ & $\begin{array}{l}\text { Youngest large deposition. } \\
\text { Mostly connected to the NW } \\
\text { ACP's margin. } \\
>\text { Locally located on the top of } \\
\text { the ACP. } \\
>\text { Progressive transition with } \\
\text { the honeycomb terrain. }\end{array}$ & $\begin{array}{c}\text { Viscous flow of an ice-rich } \\
\text { material starting from the } \\
\text { central ACP toward the } \\
\text { north. }\end{array}$ \\
\hline Two plain deposits (P1 and P2). & $\begin{array}{l}>\text { P1: presence of local round- } \\
\text { shaped knobs. } \\
>\quad \text { P2: numerous angular pits on } \\
\text { HiRISE images. } \\
>\quad \text { P1 and P2:fine-grained } \\
\text { material. }\end{array}$ & $\begin{array}{l}>\mathrm{P} 1 \text { embayed by } \mathrm{P} 2 \rightarrow \mathrm{P} 1 \\
\text { older than } \mathrm{P} 2 \\
\mathrm{P} 2 \text { overlaps the } \mathrm{ACP} \text { in the } \\
\text { east } \rightarrow \mathrm{P} 2 \text { younger than the } \\
\mathrm{ACP}\end{array}$ & $\begin{array}{l}>\text { Deposition, erosion and } \\
\text { remobilization of ice-rich } \\
\text { mantle deposit. } \\
>\text { Deposition of suspended } \\
\text { material in a paleo-lake. } \\
>\text { Effusive low viscosity lava } \\
\text { flows. }\end{array}$ \\
\hline $\begin{array}{l}\text { Two reticulate terrains: RT1 in the } \\
\text { W Hellas, RT2 in the NW Hellas. }\end{array}$ & $\begin{array}{l}>\quad \begin{array}{l}\text { Polygonal ridges separated } \\
\text { by flat depression. }\end{array} \\
>\quad \text { RT1: depressions of } 1-2 \mathrm{~km} \\
\text { across. } \\
>\quad \text { RT2: depressions of } 250- \\
\text { 1,000 m across. }\end{array}$ & $\begin{array}{l}>\mathrm{RT} 1 \text { overlaid by } \mathrm{P} 1 \rightarrow \mathrm{RT} 1 \\
\text { older than } \mathrm{P} 1 \text { and } \mathrm{P} 2 . \\
\mathrm{RT} 2 \text { enclosed in } \mathrm{P} 2 \rightarrow \mathrm{RT} 2 \\
\text { younger than } \mathrm{P} 1 \text { and younger } \\
\text { or concurrent to } \mathrm{P} 2 .\end{array}$ & $\begin{array}{c}>\text { Periglacial degradation of } \\
\text { P2. }\end{array}$ \\
\hline Honeycomb terrain. & $\begin{array}{l}>\text { Cells: depressions with } \\
\text { ridges more or less distinct. } \\
\text { Cemented sand-sized } \\
\text { material. }\end{array}$ & $\begin{array}{l}>\quad \text { Enclosed in P2. } \\
>\quad \text { Cells deformed RT2 ridges } \\
\rightarrow \text { post-dates RT } 2 . \\
>\quad \text { Some cells contains banded } \\
\text { terrain } \rightarrow \text { older than banded } \\
\text { terrain }\end{array}$ & $\begin{array}{l}>\text { Ice diapirism: extrusion of } \\
\text { over-pressured ice buried } \\
\text { below the surface. } \\
>\text { Magmatic diapirism. } \\
>\text { Salt diapirism. }\end{array}$ \\
\hline
\end{tabular}

